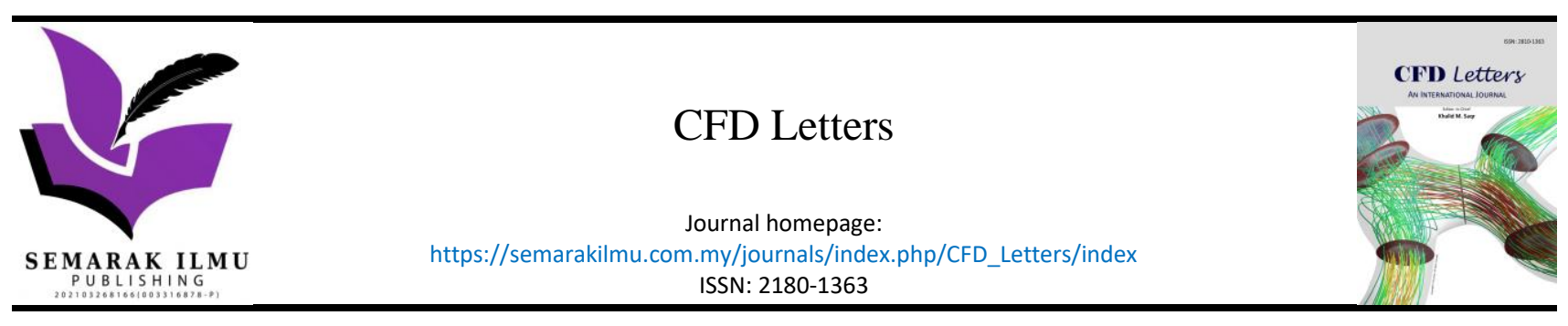

\title{
Stability Solution of Unsteady Stagnation-Point Flow and Heat Transfer over a Stretching/Shrinking Sheet in Nanofluid with Slip Velocity Effect
}

\author{
Nor Fadhilah Dzulkifli ${ }^{1}$, Norfifah Bachok ${ }^{2}$, Nor Azizah Yacob $^{1,}{ }^{*}$, loan Pop ${ }^{3}$, Norihan Arifin ${ }^{2}$, Haliza \\ Rosali $^{2}$ \\ 1 Department of Mathematics, Faculty of Computer and Mathematics Sciences, Universiti Teknologi MARA Pahang, 26400 Bandar Pusat Jengka, \\ Pahang, Malaysia \\ 2 Department of Mathematics and Institute for Mathematical Research, Universiti Putra Malaysia, 43400 UPM, Serdang Selangor, Malaysia \\ 3 Department of Mathematics, Babes-Bolyai University, 400084 Cluj-Napoca, Romania
}

\section{ARTICLE INFO}

\section{Article history:}

Received 13 September 2021 Received in revised form 11 December 2021

Accepted 12 December 2021

Available online 7 January 2022

\section{Keywords:}

Nanofluid; Slip velocity; Stability analysis; Stagnation-point flow; Stretching/ shrinking; Unsteady boundary layer

\section{ABSTRACT}

\begin{abstract}
Computational of unsteady flow with slip condition is essential since physically the heat transfer process is time-dependent and there may exist slip between fluid and surface. Therefore, this study aims to investigate the unsteady stagnation-point flow and heat transfer over a stretching/shrinking sheet immersed in nanofluid in the presence of slip velocity. By applying boundary layer theory and Tiwari-Das model, the governing equations are developed and transformed into a system of ordinary differential equations using similarity transformation, which are then solved numerically using bvp4c solver in MATLAB. The influence of slip velocity, stretching/shrinking parameters, nanoparticle volume fraction and unsteadiness parameter on the local skin friction coefficient, local Nusselt number, as well as velocity and temperature profiles are analysed. There are three types of nanoparticles considered, namely Copper $(\mathrm{Cu})$, Alumina $\left(\mathrm{Al}_{2} \mathrm{O}_{3}\right)$, Titania $\left(\mathrm{TiO}_{2}\right)$ and water $\left(\mathrm{H}_{2} \mathrm{O}\right)$ is the base fluid. It is found that dual solutions occur for certain parameters and the stability analysis is performed. The analysis shows that the first solutions are found to be stable than the second solution. The local skin friction coefficient and local Nusselt number are increasing with slip velocity, nanoparticle volume fraction for shrinking case; however, the opposite trend is observed for stretching case. By raising $20 \%$ of nanoparticle volume fraction for the shrinking sheet $(\varepsilon=-0.8$ ) the friction at the surface increases $24 \%$ and $15.5 \%$ for heat transfer rate for the first solution. Moreover, for $10 \%$ of nanoparticle volume fraction for the shrinking sheet $(\varepsilon=-0.8)$ and the first solution, varying slip parameters from 0 to 0.2 , give rise to approximately $21 \%$ of the friction at the surface and $68 \%$ of the heat transfer rate.
\end{abstract}

\section{Introduction}

In 1911, Hiemenz published the first analysis of stagnation-point flow, which was later improved by Howarth. This type of flow explains the motion of the fluid near the stagnation [1]. The local velocity of a fluid is zero at a stagnation-point point and based on the Bernoulli equation, the static

\footnotetext{
* Corresponding author.

E-mail address: norazizah872@uitm.edu.my (Nor Azizah Yacob)
} 
pressure is the highest at this point [2]. Many researchers have applied the idea of stagnation-point flow by Hiemenz in various fields. For instance, Yang et al., [3] investigated the deposition of bacteria and particles to enamels and Montecchio et al., [4] applied this flow concept in screening and testing photocatalysis in air purification applications. Bachok et al., [5], Bhattacharyya [6], Aman et al., [7], and Sharma et al., [8] have considered this flow over distinct surfaces such as stretching/shrinking sheet. Other surfaces that have been taken into account are porous plate, rotating plate, cylinder, and moving plate which were investigated by Ishak et al., [9], Hayat and Nawaz [10], Lok et al., [11], and Roşca et al., [12], respectively. The effects of radiation and magnetic field were investigated by Mahabaleshwar et al., [13], Ghasemi and Hatami [14], and Mathew et al., [15] in viscous fluid, nanofluid and silver-blood nanofluid, respectively. The stagnation-point flow case also attracted Aly and Pop [16] to analyse the effect of MHD and Jamaludin et al., [17] considered MHD and mixed convection flow over stretching/shrinking surface in a hybrid nanofluid. Zainal et al., [18] investigated similar problem by considering convection boundary conditions toward a vertical plate. Recently, Uddin et al., [19] applied Metaheuristic approach to investigate the flow over a stretching/shrinking sheet with a non-aligned axis of symmetry in nanofluid.

Nanofluid has gained significant attention due to its advantages; for instance, it can widen the surface area where the thermal conductivity and heat transfer process can be enhanced. Nanofluid is beneficial, for example, as an innovative coolant where it can also contribute to energy saving for HVAC systems, reduce fuel consumption and enhance the efficiency of the vehicle [20,21]. In 2006, Boungiorno [22] introduced a new nanofluid model that taking into account two essential slip mechanisms which are Brownian diffusion and thermophoresis. Later, in 2007, Tiwari and Das [23] developed a new nanofluid model that considers nanoparticle volume fraction into account when analysing nanofluid behaviour. Since then, many studies were conducted using these two models on the steady and unsteady flows with various effects and circumstances. The Tiwari-Das model was applied by Devi and Andrews [24], Bachok et al., [5], Srinivasacharya et al., [25], Malvandi et al., [26], Jafar et al., [27], and Ferdows et al., [28]. More interesting studies in nanofluid can be found in the previous researches [29-37].

Classical Navier-Stokes equations assume a no-slip condition at the surface; however, this assumption should be replaced since the slip between fluid and a surface may occur in some instances, as reported by Wang [38]. Jamil and Khan [39] have found the importance of boundary slip-condition in technological applications in polishing the artificial heart valves, rarefied fluid cases, etc. They have also included slip-condition in their research, which proved that slip parameter affected the velocity and shear stress at the surface. Mukhopadhyay [40] has discovered the effect of slip condition on MHD boundary layer flow for exponentially stretching sheet where the velocity and temperature profiles decreased with increasing slip velocity and slip temperature, respectively. The slip effect was also considered by Pandey and Kumar [41], Hussain et al., [42], Aly and Pop [16], and Aladdin et al., [43] for various studies in nanofluid, Casson fluid and hybrid nanofluid.

Nowadays, most numerical studies in heat transfer problems have discovered multiple solutions that require researchers to investigate the stability of the solutions as performed by Merkin [44]. In this study, Merkin [44] analysed the solutions by applying a time-dependent problem of mixed convection flow in a porous medium. Based on this study, the results indicated that the upper branch (first solution) was stable, and the lower branch (second solution) was unstable. As a continuation of Merkin [44], Weidman et al., [45] performed the equivalent analysis to determine the stability of the solution for several values of the transpiration parameter. The results showed the same conclusion as previous work. Further, it had inspired other researchers to perform the stability analysis to validate the stability and realizable solution, such as Harris et al., [46], Mahapatra et al., [47], Roşca and Pop [48], Ishak [49], Jamaludin et al., [17], and Aladdin et al., [43]. 
In the previous study, Bachok et al., [5] analysed an unsteady flow towards a stagnation-point on a flat surface using the Tiwari-Das model by taking three types of nanoparticles: $\mathrm{Cu}, \mathrm{Al}_{2} \mathrm{O}_{3}$, and $\mathrm{TiO}_{2}$ in $\mathrm{H}_{2} \mathrm{O}$. This study aims to extend the work of Bachok et al., [5] by considering the effect of slip velocity over a stretching/shrinking surface with stability analysis. The numerical results from this mathematical model with unsteady and velocity slip condition have not been presented yet. Therefore, the results obtained are new and can be used in many practical applications. However, many studies have been done for other mathematical models with these effects. The numerical solutions are obtained by bvp4c solver in MATLAB software which are then tabulated and displayed graphically.

\section{Methodology}

Consider a two-dimensional laminar incompressible stagnation-point flow where the unsteady free stream velocity is $U_{\infty}=a x /(1-c t), a(>0)$ and $c$ are constants. The sheet velocity is $u_{w}=b x /(1-c t)$ where $b>0$ for stretching sheet, $b<0$ shrinking sheet and $t$ denotes time. Assuming the temperature of the surface and ambient temperature are $T_{w}$ and $T_{\infty}$, respectively, where both are constants and $x$ - axis is parallel to stream direction while $y$-axis is perpendicular to it. Apart from that, consider the slip between fluid and surface represented by $u_{s}=L(\partial u / \partial y)$, where $L$ is the length of the slip [50]. The physical model of the problem is shown in Figure 1.

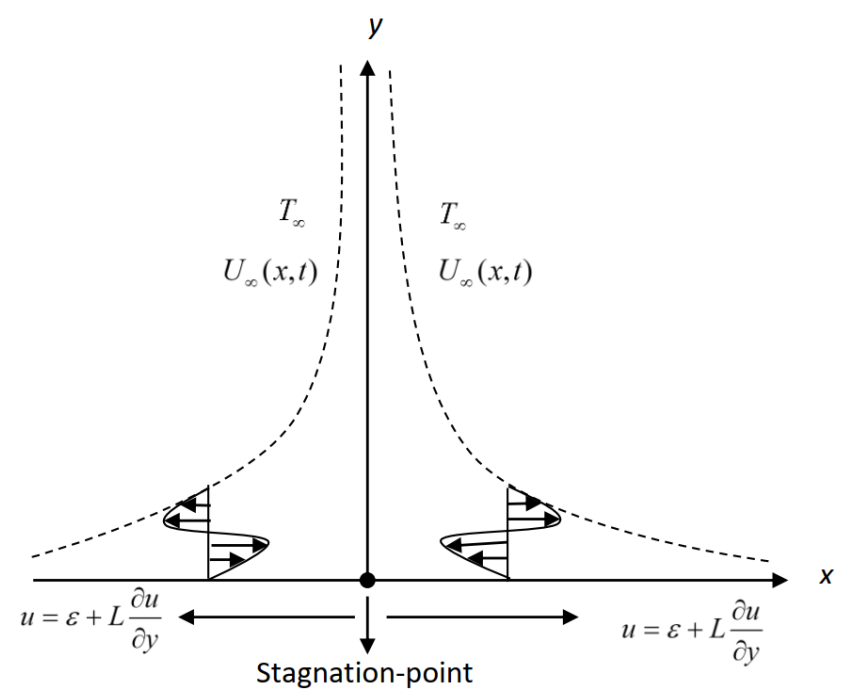

Fig. 1. The schematic diagram of physical model

The governing equations of the above system are given as follows [5]:

$$
\begin{aligned}
& \frac{\partial u}{\partial x}+\frac{\partial v}{\partial y}=0 \\
& \frac{\partial u}{\partial t}+u \frac{\partial u}{\partial x}+v \frac{\partial u}{\partial y}=U_{\infty} \frac{\partial U_{\infty}}{\partial x}+\frac{\mu_{n f}}{\rho_{n f}} \frac{\partial^{2} u}{\partial y^{2}}
\end{aligned}
$$




$$
\frac{\partial T}{\partial t}+u \frac{\partial T}{\partial x}+v \frac{\partial T}{\partial y}=\alpha_{n f} \frac{\partial^{2} T}{\partial y^{2}}
$$

subject to the boundary conditions

$$
\begin{aligned}
& u=u_{w}+L \frac{\partial u}{\partial y}, v=0, T=T_{w} \text { at } y=0, \\
& u \rightarrow U_{\infty}, T \rightarrow T_{\infty} \text { as } y \rightarrow \infty,
\end{aligned}
$$

where $u$ and $v$ are the velocity components in $x$ - and $y$-axes, and $T$ is the nanofluid temperature. The dynamic viscosity of nanofluid $\mu_{n f}$, thermal diffusivity of nanofluid $\alpha_{n f}$, effective thermal conductivity of nanofluids $k_{n f} / k_{f}$, density of nanofluid $\rho_{n f}$, and heat capacitance of nanofluid $\left(\rho c_{p}\right)_{n f}$ are given as follows [51]:

$$
\begin{aligned}
& \mu_{n f}=\frac{\mu_{f}}{(1-\varphi)^{2.5}}, \alpha_{n f}=\frac{k_{n f}}{\left(\rho c_{p}\right)_{n f}}, \frac{k_{n f}}{k_{f}}=\frac{\left(k_{s}+2 k_{f}\right)-2 \varphi\left(k_{f}-k_{s}\right)}{\left(k_{s}+2 k_{f}\right)+\varphi\left(k_{f}-k_{s}\right)} \\
& \rho_{n f}=\rho_{f}\left[1-\varphi+\varphi\left(\frac{\rho_{s}}{\rho_{f}}\right)\right],\left(\rho c_{p}\right)_{n f}=\left(\rho c_{p}\right)_{f}\left[1-\varphi+\varphi\left(\frac{\left(\rho c_{p}\right)_{s}}{\left(\rho c_{p}\right)_{f}}\right)\right],
\end{aligned}
$$

where $\varphi$ denotes the nanoparticle volume fraction, $\mu_{f}$ is the dynamic viscosity of the fluid, $\rho_{f}$ is the density of fluid, $k_{f}, k_{n f}$ and $k_{s}$ are the thermal conductivities of the fluid, nanofluid and nanoparticle, respectively. The terms of $\left(\rho c_{p}\right)_{f}$, and $\left(\rho c_{p}\right)_{s}$ are the heat capacitance of the fluid and nanoparticle, respectively.

The system of Eq. (1) to Eq. (3) bounded by Eq. (4) was transformed to the ordinary differential equations using the similarity variables which are given by:

$$
\eta=\left(\frac{a}{v_{f}(1-c t)}\right)^{1 / 2} y, \quad \psi=\left(\frac{v_{f} a}{1-c t}\right)^{1 / 2} \times f(\eta), \quad \theta(\eta)=\frac{T-T_{\infty}}{T_{w}-T_{\infty}}
$$

then we obtain

$$
\begin{aligned}
& \frac{1}{(1-\varphi)^{2.5}\left[1-\varphi+\varphi\left(\rho_{s} / \rho_{f}\right)\right]} f^{\prime \prime \prime}+f f^{\prime \prime}-f^{\prime 2}+1-A\left(f^{\prime}+\frac{\eta}{2} f^{\prime \prime}-1\right)=0, \\
& \frac{1}{\operatorname{Pr}} \frac{k_{n f}}{k_{f}\left[1-\varphi+\varphi\left(\left(\rho c_{p}\right)_{s} /\left(\rho c_{p}\right)_{f}\right)\right]} \theta^{\prime \prime}+\left(f-\frac{A}{2} \eta\right) \theta^{\prime}=0,
\end{aligned}
$$


subject to the boundary conditions

$$
\begin{aligned}
& f(0)=0, f^{\prime}(0)=\varepsilon+\sigma f^{\prime \prime}(0), \quad \theta(0)=1 \text { at } \eta=0, \\
& f^{\prime}(\eta) \rightarrow 1, \quad \theta(\eta) \rightarrow 0 \text { as } \eta \rightarrow \infty .
\end{aligned}
$$

where $\psi$ is the stream function in which $u=\partial \psi / \partial y$ and $v=-\partial \psi / \partial x$ satisfy Eq. (1). Here, prime (') denotes the differentiation with respect to $\eta, v_{f}$ is the kinematic viscosity of fluid, $\sigma$ is the slip velocity parameter, $\operatorname{Pr}$ is the PrandtI number, $A=c / a$ is the unsteadiness parameter, and $\varepsilon=b / a$ is the velocity ratio parameter.

The physical quantities of interests, namely local skin friction coefficient $C_{f}$ and local Nusselt number $N u_{x}$ are given by

$$
C_{f}=\frac{\tau_{w}}{\rho_{f} U_{\infty}^{2}}, \quad N u_{x}=\frac{x q_{w}}{k_{f}\left(T_{w}-T_{\infty}\right)}
$$

where $\tau_{w}$ is the shear stress and $q_{w}$ is the heat flux at the surface, which are represented by

$$
\tau_{w}=\mu_{n f}\left(\frac{\partial u}{\partial y}\right)_{y=0}, \quad q_{w}=-k_{n f}\left(\frac{\partial T}{\partial y}\right)_{y=0}
$$

Using Eq. (6), Eq. (10), and Eq. (11), we obtain

$$
C_{f} \operatorname{Re}_{x}^{1 / 2}=\frac{1}{(1-\varphi)^{2.5}} f^{\prime \prime}(0), N u_{x} \operatorname{Re}_{x}^{-1 / 2}=-\frac{k_{n f}}{k_{f}} \theta^{\prime}(0)
$$

where $\operatorname{Re}_{x}=U_{\infty} x / v$ denotes the local Reynolds number.

\section{Method of Solutions}

A bvp4c solver in MATLAB was used to solve the system of ordinary differential Eq. (7) and Eq. (8) subject to boundary conditions (9) numerically as described by Shampine et al., [52]. The numerical solutions were obtained using the following steps:

(i) Reduce Eq. (7) to Eq. (9) to a first-order system by introducing new dependent variables such that $f=y(1), f^{\prime}=y(2), f^{\prime \prime}=y(3), \theta=y(4), \theta^{\prime}=y(5)$.

(ii) Define the ODEs in MATLAB coding by writing a $1 \times 5$ matrix that contains $f^{\prime}, f^{\prime \prime}, f^{\prime \prime \prime}, \theta$ and $\theta^{\prime}$ in terms of the dependent variables above.

(iii) Define the boundary conditions (9) in MATLAB coding in terms of the dependent variables above by letting the right side of the equations becomes 0 .

(iv) Set up the initial guesses and boundary layer thicknesses for the first and second solutions, respectively, to get the profiles that fulfill the boundary conditions (9) asymptotically. 


\section{Stability Analysis}

In this paper, the existence of dual solutions requires a stability analysis to be performed to determine the stability of the solutions. A dimensionless time variable $\tau$ was introduced to implement the stability analysis, and the new similarity variables are given by

$$
\tau=\frac{a t}{1-c t}, \eta=\left(\frac{a}{v_{f}(1-c t)}\right)^{1 / 2} y, \psi=\left(\frac{v_{f} a}{1-c t}\right)^{1 / 2} \times f(\eta, \tau), \theta(\eta, \tau)=\frac{T-T_{\infty}}{T_{w}-T_{\infty}}
$$

Using new dimensionless similarity variables (13), Eq. (2) and Eq. (3) subject to Eq. (4) were transformed to the following equations [45],

$$
\begin{aligned}
& \frac{1}{(1-\varphi)^{2.5}\left[1-\varphi+\varphi\left(\rho_{s} / \rho_{f}\right)\right]} \frac{\partial^{3} f}{\partial \eta^{3}}+f \frac{\partial^{2} f}{\partial \eta^{2}}-\left(\frac{\partial f}{\partial \eta}\right)^{2}+1-A\left(\frac{\partial f}{\partial \eta}+\frac{\eta}{2} \frac{\partial^{2} f}{\partial \eta^{2}}-1\right) \\
& -\frac{1}{1-c t} \frac{\partial^{2} f}{\partial \eta \partial \tau}=0,
\end{aligned}
$$

$$
\frac{1}{\operatorname{Pr}} \frac{k_{n f}}{k_{f}\left[1-\varphi+\varphi\left(\left(\rho c_{p}\right)_{s} /\left(\rho c_{p}\right)_{f}\right)\right]} \frac{\partial^{2} \theta}{\partial \eta^{2}}+\left(f-\frac{A}{2} \eta\right) \frac{\partial \theta}{\partial \eta}-\frac{1}{1-c t} \frac{\partial \theta}{\partial \tau}=0,
$$

subject to the boundary conditions

$$
\begin{aligned}
& f(0, \tau)=0, \frac{\partial f}{\partial \eta}(0, \tau)=\varepsilon+\sigma \frac{\partial^{2} f}{\partial \eta^{2}}(0, \tau), \quad \theta(0, \tau)=1 \quad \text { at } \quad \eta=0, \\
& \frac{\partial f}{\partial \eta}(\eta, \tau) \rightarrow 1, \theta(\eta, \tau) \rightarrow 0 \quad \text { as } \eta \rightarrow \infty
\end{aligned}
$$

To test the stability of solutions, let $f(\eta)=f_{0}(\eta)$ and $\theta(\eta)=\theta_{0}(\eta)$ that satisfy the boundary value problem (7)-(9) and by writing the following equations as mentioned by Weidman et al., [45],

$$
f(\eta, \tau)=f_{0}(\eta)+e^{-\gamma \tau} F_{0}(\eta), \text { and } \theta(\eta, \tau)=\theta_{0}(\eta)+e^{-\gamma \tau} G_{0}(\eta)
$$

where $\gamma$ is unknown eigenvalue parameter, and $F_{0}(\eta)$ and $G_{0}(\eta)$ are small relative to $f_{0}(\eta)$ and $\theta_{0}(\eta)$, respectively. Substituting Eq. (17) into Eq. (14) to Eq. (16) and let $\tau=0$, we obtain the following equations:

$$
\frac{1}{(1-\varphi)^{2.5}\left[1-\varphi+\varphi\left(\rho_{s} / \rho_{f}\right)\right]} F_{0}^{\prime \prime \prime}+f_{0} F_{0}^{\prime \prime}+f_{0}^{\prime \prime} F_{0}-2 f_{0}^{\prime} F_{0}^{\prime}-A\left(F_{0}^{\prime}+F_{0}^{\prime \prime}\right)+\gamma F_{0}^{\prime}=0
$$




$$
\frac{1}{\operatorname{Pr}} \frac{k_{n f}}{k_{f}\left[1-\varphi+\varphi\left(\left(\rho c_{p}\right)_{s} /\left(\rho c_{p}\right)_{f}\right)\right]} G_{0}^{\prime \prime}+f_{0} G_{0}^{\prime}+F_{0} \theta_{0}^{\prime}-\frac{A \eta}{2} G_{0}^{\prime}+\gamma G_{0}=0
$$

subject to the boundary conditions

$$
\begin{aligned}
& F_{0}(0)=0, F_{0}^{\prime}(0)-\sigma F_{0}^{\prime \prime}(0)=0, \quad G_{0}(0)=0 \text { at } \eta=0, \\
& F_{0}^{\prime}(\eta) \rightarrow 0, G_{0}(\eta) \rightarrow 0 \text { as } \eta \rightarrow \infty .
\end{aligned}
$$

The stability of the flow solutions $f_{0}(\eta)$ and $\theta_{0}(\eta)$ for particular values of the parameters is determined by the smallest eigenvalue $\gamma$, where the positive eigenvalue indicates that the flow is stable while negative eigenvalue shows the unstable flow [45]. Eq. (18) to Eq. (20) were reduced to a first-order system using similar procedures mentioned in Section 3 to determine the smallest eigenvalue $\gamma$. According to Harris et al., [46], the range of possible eigenvalues $\gamma$ can be obtained by relaxing a boundary condition on $F_{0}(\eta)$ or $G_{0}(\eta)$. The boundary condition $F_{0}^{\prime}(\eta) \rightarrow 0$ as $\eta \rightarrow \infty$ is chosen to be relaxed, then the Eq. (19) to Eq. (21) were solved using bvp4c solver in MATLAB software with the new boundary condition $F_{0}^{\prime \prime}(0)=1$ to obtain the values of $\gamma$.

\section{Results and Discussion}

In this paper, water $\left(\mathrm{H}_{2} \mathrm{O}\right)$ was chosen as a base fluid and three types of nanoparticles were selected: $\mathrm{Cu}, \mathrm{Al}_{2} \mathrm{O}_{3}$, and $\mathrm{TiO}_{2}$. According to Oztop and Abu-Nada [51], the nanoparticle volume fraction $\varphi$ was taken between 0 to $0.2(0-20 \%)$ where $\varphi=0$ represents the regular fluid, and Prandt number $\operatorname{Pr}=6.2$. Besides, the thermophysical properties as presented in Table 1 give the values of density, specific heat as well as conductivity of water and nanoparticles [51]. The numerical solutions obtained as described in Section 3 were presented in tables and graphs. The comparison of numerical results with Bachok et al., [5] has been made and presented in Table 2 with different values of unsteadiness parameter $A$ for $\mathrm{Cu}-\mathrm{H}_{2} \mathrm{O}$ nanofluid where it shows an excellent agreement and portrays that the present results are accurate. It is found that dual solutions are obtained for certain parameters as displayed in Table 2 and Table 3 as well as in Figure 2 to Figure 15 and Figure 17 to Figure 25. Dual solutions are obtained by setting two different boundary layer thicknesses under the same boundary conditions, producing two different velocity and temperature profiles that satisfy the boundary conditions. Based on this result, it gives two values of local skin friction coefficient $f^{\prime \prime}(0)$ and local Nusselt number $-\theta^{\prime}(0)$. Dual solutions can be categorized as first and second solutions (upper and lower branches). According to Merkin [44], the first solution is stable, whereas the second solution has no physical meaning. Nevertheless, it is vital from a mathematical standpoint because it may make physical sense in other cases.

Table 3 depicts the values of $f^{\prime \prime}(0)$ and $-\theta^{\prime}(0)$ for $\varepsilon=-0.5$ (shrinking sheet) and several values $A$ for different types of nanofluid when the nanoparticle volume fraction $\varphi=0.1$ and the slip parameter $\sigma=0.1$ are taken into account. As shown in Table 3, the result indicates that $\mathrm{Cu}$ has the highest value for both $\left|f^{\prime \prime}(0)\right|$ and $\left|-\theta^{\prime}(0)\right|$ as compared to $\mathrm{Al}_{2} \mathrm{O}_{3}$, and $\mathrm{TiO}_{2}$ since $\mathrm{Cu}$ has the highest thermal conductivity. 
Table 1

Thermophysical properties of water and nanoparticles [51]

\begin{tabular}{llll}
\hline Substance & $\begin{array}{l}\text { Density, } \rho \\
\left(\mathrm{kg} / \mathrm{m}^{3}\right)\end{array}$ & $\begin{array}{l}\text { Specific heat, } c_{p} \\
(\mathrm{~J} / \mathrm{kg} \mathrm{K})\end{array}$ & $\begin{array}{l}\text { Conductivity, } k \\
(\mathrm{~W} / \mathrm{m} \mathrm{K})\end{array}$ \\
\hline Water & 997.1 & 4179 & 0.613 \\
Copper, $\mathrm{Cu}$ & 8933 & 385 & 400 \\
Alumina, $\mathrm{Al}_{2} \mathrm{O}_{3}$ & 3970 & 765 & 40 \\
Titania, $\mathrm{TiO}_{2}$ & 4250 & 686.2 & 8.9538 \\
\hline
\end{tabular}

Table 2

Comparison values of $f^{\prime \prime}(0)$ and $-\theta^{\prime}(0)$ for different values of $A$ and $\mathrm{Cu}-\mathrm{H}_{2} \mathrm{O}$ nanofluid when $\varphi=0.1, \varepsilon=0, \sigma=0$ and $\operatorname{Pr}=6.2$

\begin{tabular}{lllll}
\hline$A$ & Bachok et al., [5] & \multicolumn{3}{l}{ Present Results } \\
& $f^{\prime \prime}(0)$ & $-\theta^{\prime}(0)$ & $f^{\prime \prime}(0)$ & $-\theta^{\prime}(0)$ \\
\hline 1 & 1.7604 & 0.4681 & 1.7604 & 0.4681 \\
-1 & 1.0845 & 1.4957 & 1.0845 & 1.4957 \\
& {$[-1.1573]$} & {$[0.4638]$} & {$[-1.1573]$} & {$[0.4638]$} \\
-2 & 0.6499 & 1.8532 & 0.6499 & 1.8532 \\
& {$[-1.9885]$} & {$[1.3327]$} & {$[-1.9885]$} & {$[1.3327]$} \\
-3 & 0.1045 & 2.1550 & 0.1045 & 2.1550 \\
& {$[-2.3251]$} & {$[1.8455]$} & {$[-2.3251]$} & {$[1.8455]$} \\
-4 & -0.6757 & 2.4089 & -0.6757 & 2.4089 \\
& {$[-2.2646]$} & {$[2.2590]$} & {$[-2.2646]$} & {$[2.2590]$} \\
\hline
\end{tabular}

$*$ [ ] denotes the second solution

\section{Table 3}

Values of $f^{\prime \prime}(0)$ and $-\theta^{\prime}(0)$ for several values of $A$ and different types of nanofluid when $\varphi=0.1, \sigma=0.1$ and $\operatorname{Pr}=6.2$ for shrinking case $(\varepsilon=-0.5)$

\begin{tabular}{lllllll}
\hline$A$ & $\mathrm{Cu}-\mathrm{H}_{2} \mathrm{O}$ & \multicolumn{3}{c}{$\mathrm{Al}_{2} \mathrm{O}_{3}-\mathrm{H}_{2} \mathrm{O}$} & \multicolumn{3}{c}{$\mathrm{TiO}_{2}-\mathrm{H}_{2} \mathrm{O}$} \\
\cline { 2 - 7 } & $f^{\prime \prime}(0)$ & $-\theta^{\prime}(0)$ & $f^{\prime \prime}(0)$ & $-\theta^{\prime}(0)$ & $f^{\prime \prime}(0)$ & $-\theta^{\prime}(0)$ \\
\hline 1 & 2.115 & 0.25735 & 1.8245 & 0.16895 & 1.8423 & 0.17022 \\
0 & 1.6935 & 0.7833 & 1.4500 & 0.6940 & 1.4650 & 0.7048 \\
-1 & 1.0845 & 1.1718 & 0.9137 & 1.1061 & 0.9241 & 1.1247 \\
& {$[-0.6296]$} & {$[0.3349]$} & {$[-0.5475]$} & {$[0.2591]$} & {$[-0.5527]$} & {$[0.2608]$} \\
\hline
\end{tabular}

*[ ] denotes the second solution

As can be observed from Figure 2 to Figure 15, dual solutions are obtained until at the critical points $\varepsilon_{c}$ and $A_{c}$ for $\varepsilon>\varepsilon_{c}$ and $A>A_{c}$, where no solution is found for $\varepsilon<\varepsilon_{c}$ and $A<A_{c}$. This phenomenon occurs due to reversed flow in the boundary layer, which forces decelerated fluid particles outwards and separates the boundary layer from the surface [1]. Based on the numerical results and plotted graphs, the range of solutions is affected by the nanoparticle concentration, velocity slip parameter, and unsteadiness parameter. Note that, in Figure 2 to Figure 5, increasing the nanoparticle volume fraction in the base fluid and velocity slip parameter increase the solutions range. In contrast, the opposite trend is observed when the graphs of $f^{\prime \prime}(0)$ and $-\theta^{\prime}(0)$ were plotted versus $A$ as displayed in Figure 6 to Figure 9. However, the range of solutions is not in order with the changes in velocity slip parameter as depicted in Figure 10 and Figure 11. Further, Figure 12 and Figure 13 portray $\mathrm{Cu}$ has the largest range of solutions $\left(\varepsilon_{c}=-1.0222\right)$ compared to $\mathrm{TiO}_{2}$ $\left(\varepsilon_{c}=-1.0135\right)$ and $\mathrm{Al}_{2} \mathrm{O}_{3}\left(\varepsilon_{c}=-1.0129\right)$. However, different findings are obtained for the graphs 
plotted with $A$ where $\mathrm{Al}_{2} \mathrm{O}_{3}$ has the largest range of solutions $\left(A_{c}=-1.7261\right)$ and $\mathrm{Cu}$ has the lowest $\left(A_{c}=-1.7243\right)$ as displayed in Figure 14 and Figure 15.

The variations of $f^{\prime \prime}(0)$ and $-\theta^{\prime}(0)$ with velocity ratio parameter $\varepsilon$ for different $\varphi$ in $\mathrm{Cu}-\mathrm{H}_{2} \mathrm{O}$ nanofluid are presented in Figure 2 and Figure 3. It is found that when the nanoparticle volume fraction increases from 0 to $0.2(0-20 \%)$, the values of $f^{\prime \prime}(0)$ increase for the first solutions for all the values of $\varepsilon$ considered. However, the values of $-\theta^{\prime}(0)$ for the first solution increase when $\varepsilon_{c}<\varepsilon<-0.85$ and decrease when $\varepsilon>-0.5$. This finding shows that as the nanoparticle concentration increases, the friction and heat transfer rate at the surface increase; however, it depends on the value of $\varepsilon$.

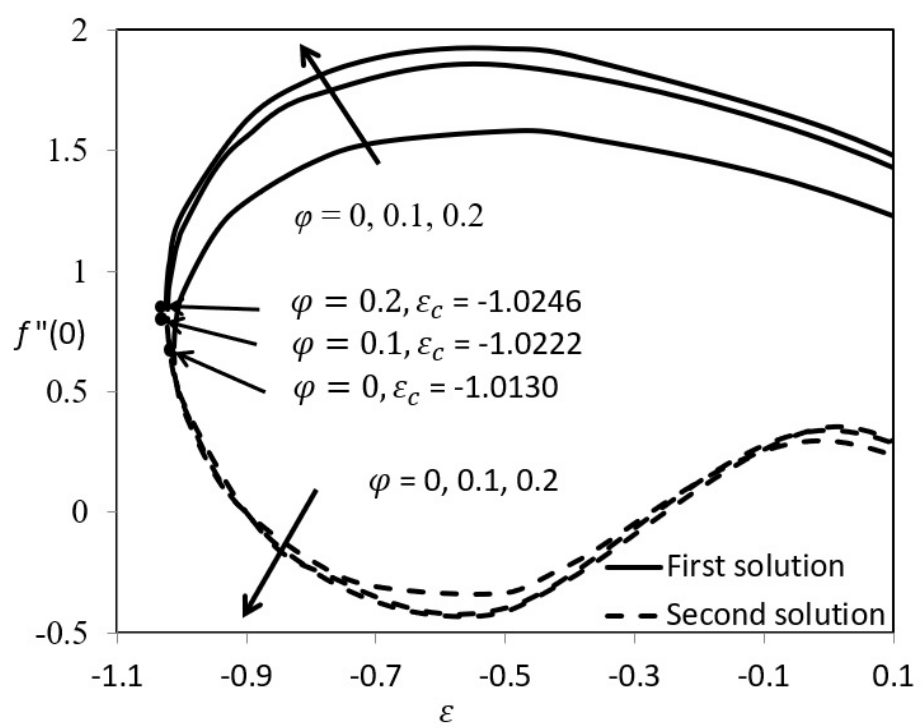

Fig. 2. Variation of $f^{\prime \prime}(0)$ with $\varepsilon$ for different values of $\varphi$ when $A=-0.5$ and $\sigma=0.1$ for $\mathrm{Cu}-\mathrm{H}_{2} \mathrm{O}$ nanofluid

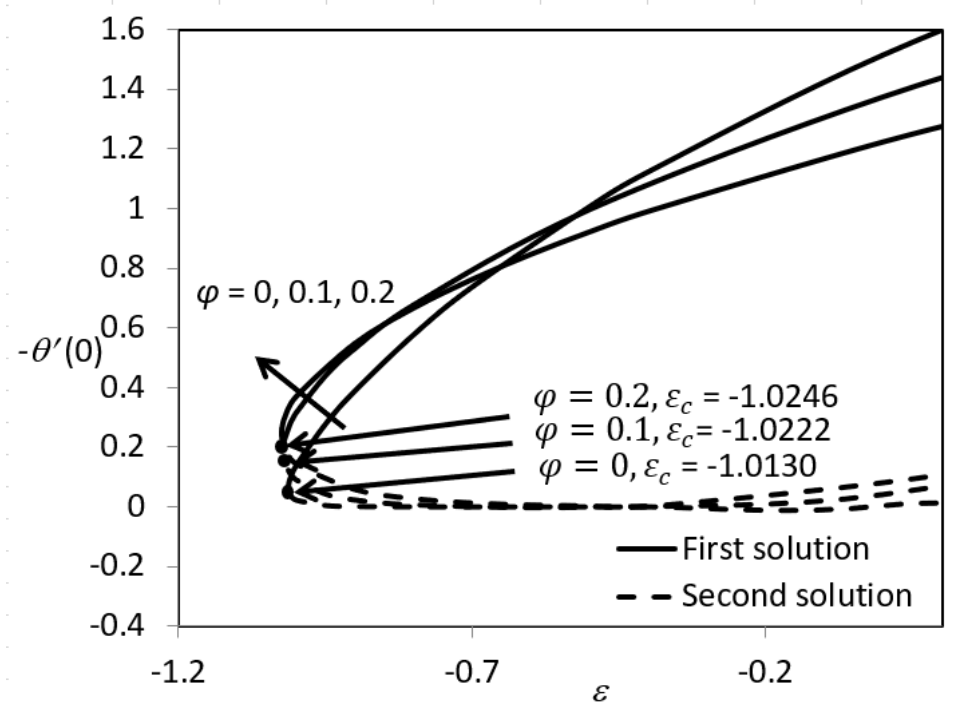

Fig. 3. Variation of $-\theta^{\prime}(0)$ with $\varepsilon$ for different values of $\varphi$ when $A=-0.5$ and $\sigma=0.1$ for $\mathrm{Cu}-\mathrm{H}_{2} \mathrm{O}$ nanofluid 
The effects of slip velocity parameter $\sigma$ on the values of $f^{\prime \prime}(0)$ and $-\theta^{\prime}(0)$ with velocity ratio parameter $\varepsilon$ are illustrated in Figure 4 and Figure 5, respectively. It is shown that increasing $\sigma$ increases the values of $f^{\prime \prime}(0)$ when $\varepsilon_{c}<\varepsilon<-0.7$ for the first and second solutions, respectively. However, for the first solution, the values of $-\theta^{\prime}(0)$ increase with $\sigma$ for all the values of $\varepsilon$ considered. Thus, it shows the heat transfer rate increases with larger slip velocity parameters. Meanwhile when $\varepsilon \rightarrow \varepsilon_{c}$, the values of $f^{\prime \prime}(0)$ and $-\theta^{\prime}(0)$ decrease for the first solutions when the shrinking process becomes dominant, as depicted in Figure 4 and Figure 5.

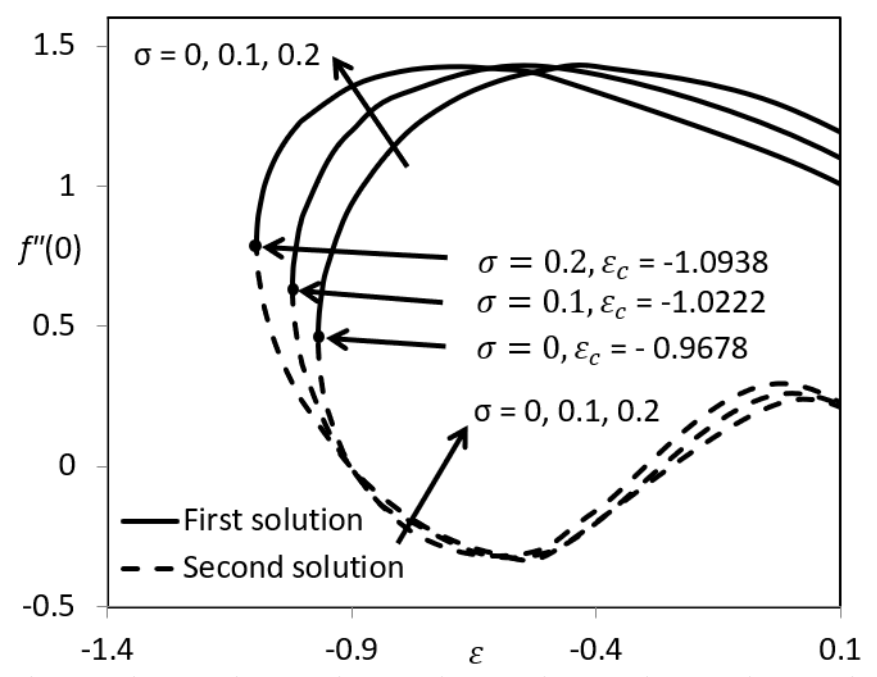

Fig. 4. Variation of $f^{\prime \prime}(0)$ with $\varepsilon$ for different values of $\sigma$ when $A=-0.5$ and $\phi=0.1$ for $\mathrm{Cu}-\mathrm{H}_{2} \mathrm{O}$ nanofluid

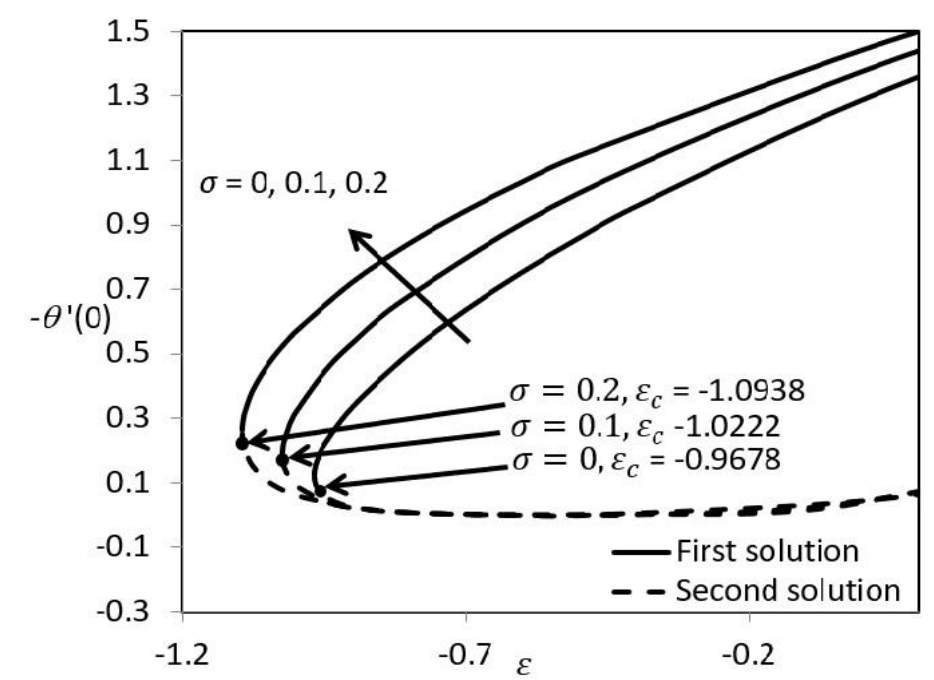

Fig. 5. Variation of $-\theta^{\prime}(0)$ with $\varepsilon$ for different of $\sigma$ when $A=-0.5$ and $\phi=0.1$ for $\mathrm{Cu}-\mathrm{H}_{2} \mathrm{O}$ nanofluid

Figure 6 and Figure 7 display the effects of nanoparticle volume fraction $\varphi$ with unsteady parameter $A$ on the values of $f^{\prime \prime}(0)$ and $-\theta^{\prime}(0)$ for shrinking case whilst Figure 8 and Figure 9 represent the stretching case. The enhancement of nanoparticle concentration in the base fluid 
increases the values of $f^{\prime \prime}(0)$ and decreases $-\theta^{\prime}(0)$ as demonstrated in Figure 6 and Figure 7, respectively. Meanwhile, the values of $f^{\prime \prime}(0)$ and $-\theta^{\prime}(0)$ decrease with increasing 0 to $20 \%$ of $\varphi$ for stretching case as shown in Figure 8 and Figure 9.

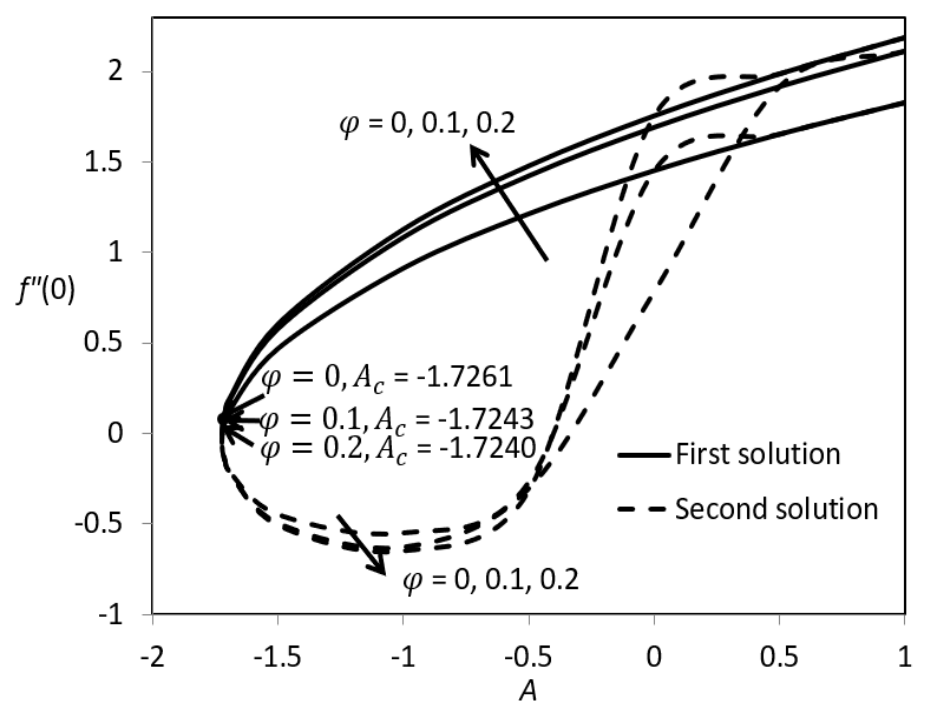

Fig. 6. Variation of $f^{\prime \prime}(0)$ with $A$ for different values of $\varphi$ when $\varepsilon=-0.5$ and $\sigma=0.1$ for $\mathrm{Cu}-\mathrm{H}_{2} \mathrm{O}$ nanofluid

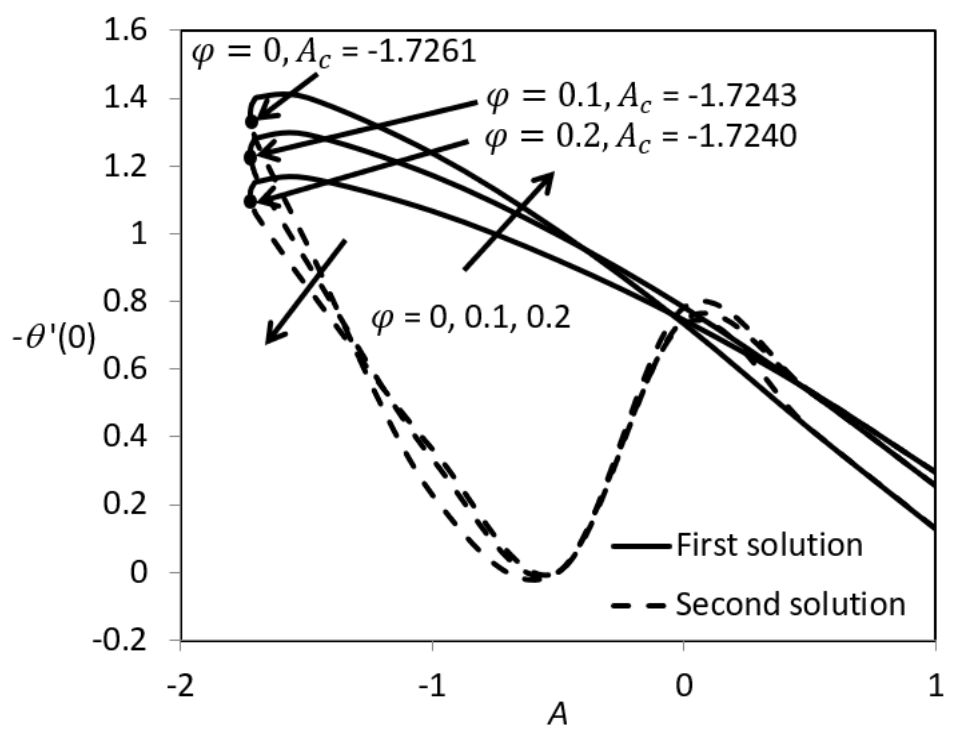

Fig. 7. Variation of $-\theta^{\prime}(0)$ with $A$ for different values of $\varphi$ when $\varepsilon=-0.5$ and $\sigma=0.1$ for $\mathrm{Cu}-\mathrm{H}_{2} \mathrm{O}$ nanofluid 


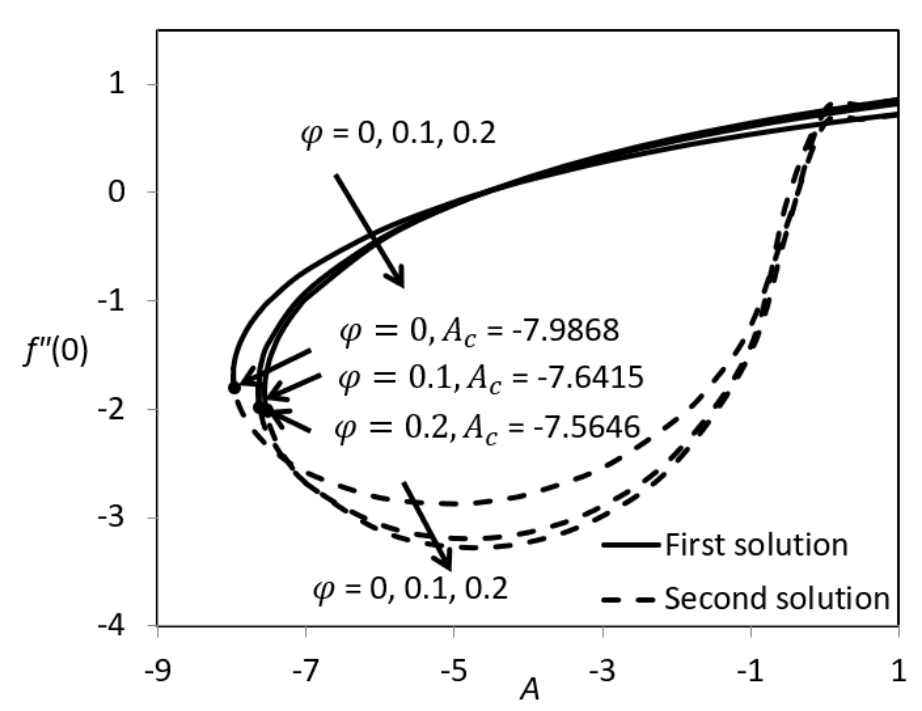

Fig. 8. Variation of $f^{\prime \prime}(0)$ with $A$ for different values of $\varphi$ when $\varepsilon=0.5$ and $\sigma=0.1$ for $\mathrm{Cu}-\mathrm{H}_{2} \mathrm{O}$ nanofluid

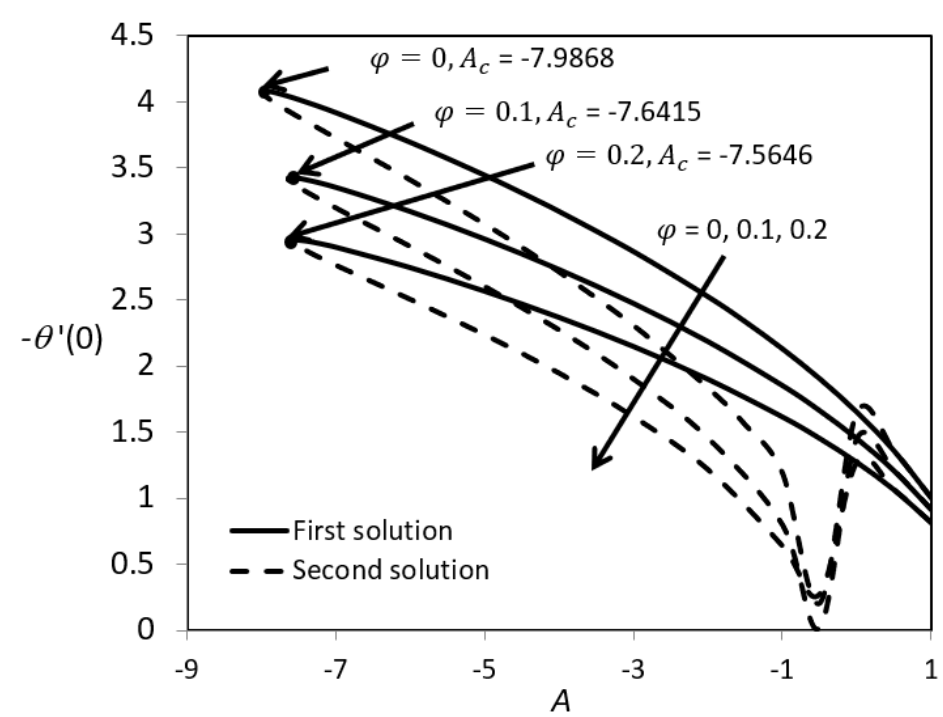

Fig. 9. Variation of $-\theta^{\prime}(0)$ with $A$ for different values of $\varphi$ when $\varepsilon=0.5$ and $\sigma=0.1$ for $\mathrm{Cu}-\mathrm{H}_{2} \mathrm{O}$ nanofluid

The effects of slip velocity parameter $\sigma$ on the values of $f^{\prime \prime}(0)$ and $-\theta^{\prime}(0)$ are illustrated in Figure 10 and Figure 11 with the unsteady parameter $A$ for $\mathrm{Cu}-\mathrm{H}_{2} \mathrm{O}$ nanofluid. It is found that the values $f^{\prime \prime}(0)$ and $-\theta^{\prime}(0)$ increase when the slip velocity between fluid and surface increases. The slip velocity is the difference between the average of fluid velocity and the average of particle velocity in a vertical flow. Therefore, a high slip velocity means the fluid velocity is higher than the particle velocity. This finding indicates that in the presence of the slip velocity parameter, the friction and heat transfer rate at the surface can be increased. 


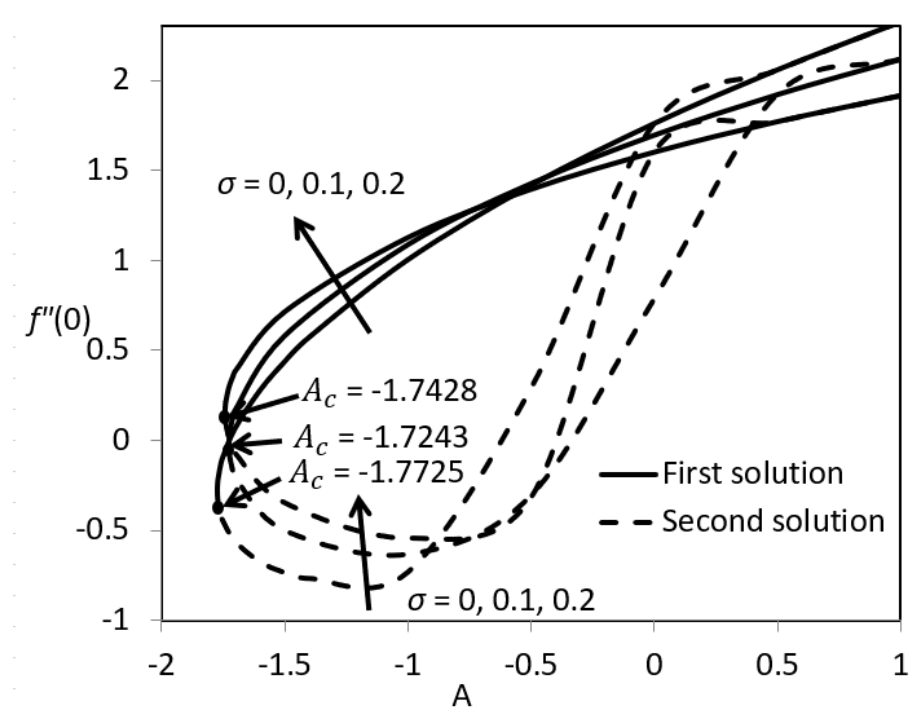

Fig. 10. Variation of $f^{\prime \prime}(0)$ with $A$ for different values of $\sigma$ when $\varepsilon=-0.5$ and $\varphi=0.1$ for $\mathrm{Cu}-\mathrm{H}_{2} \mathrm{O}$ nanofluid

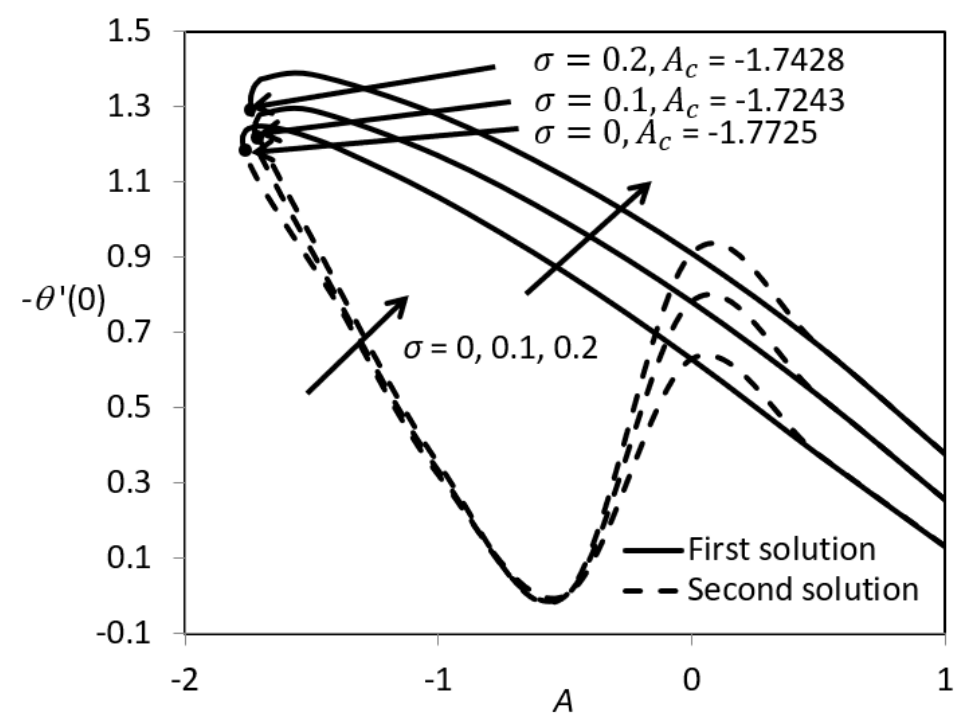

Fig. 11. Variation of $-\theta^{\prime}(0)$ with $A$ for different values of $\sigma$ when $\varepsilon=-0.5$ and $\varphi=0.1$ for $\mathrm{Cu}-\mathrm{H}_{2} \mathrm{O}$ nanofluid

Figure 12 and Figure 13 show the variation of $f^{\prime \prime}(0)$ and $-\theta^{\prime}(0)$ versus velocity ratio parameter $\varepsilon$, whilst Figure 14 and Figure 15 were plotted versus unsteadiness parameter $A$ for different nanoparticles, namely $\mathrm{Cu}, \mathrm{Al}_{2} \mathrm{O}_{3}$, and $\mathrm{TiO}_{2}$. It can be seen that $\mathrm{Cu}$ has the highest values of $f^{\prime \prime}(0)$ and $-\theta^{\prime}(0)$ which represent the friction and heat transfer rate at the surface followed by $\mathrm{TiO}_{2}$ and $\mathrm{Al}_{2} \mathrm{O}_{3}$, respectively. 


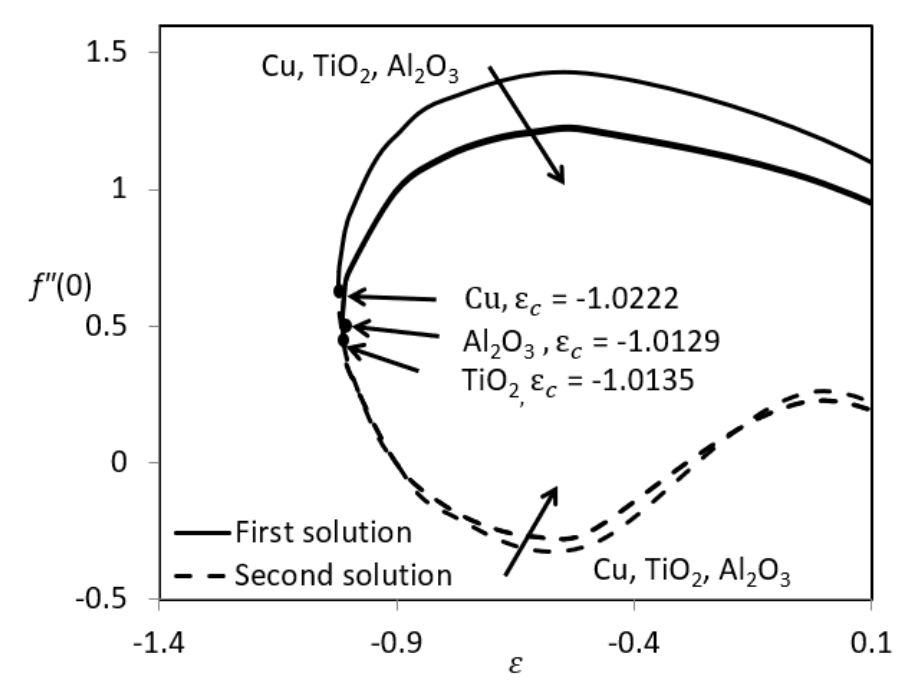

Fig. 12. Variation of $f^{\prime \prime}(0)$ with $\varepsilon$ for different nanoparticles when $A=0.5, \sigma=0.1$ and $\varphi=0.1$ for $\mathrm{Cu}^{-} \mathrm{H}_{2} \mathrm{O}$ nanofluid

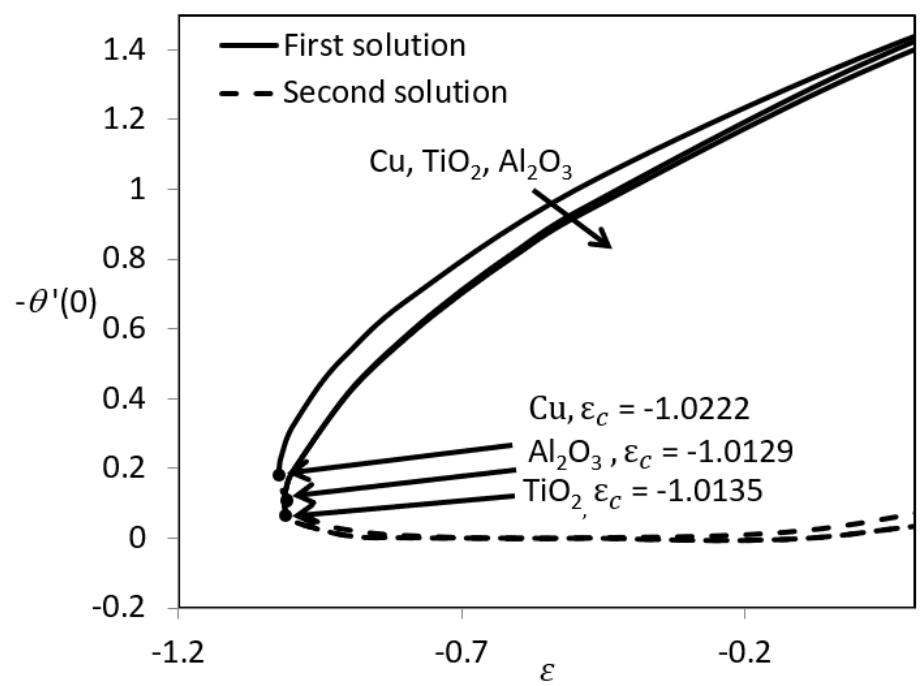

Fig. 13. Variation of $-\theta^{\prime}(0)$ with $\varepsilon$ for different nanoparticles when $A=0.5, \sigma=0.1$ and $\varphi=0.1$ for $\mathrm{Cu}-\mathrm{H}_{2} \mathrm{O}$ nanofluid

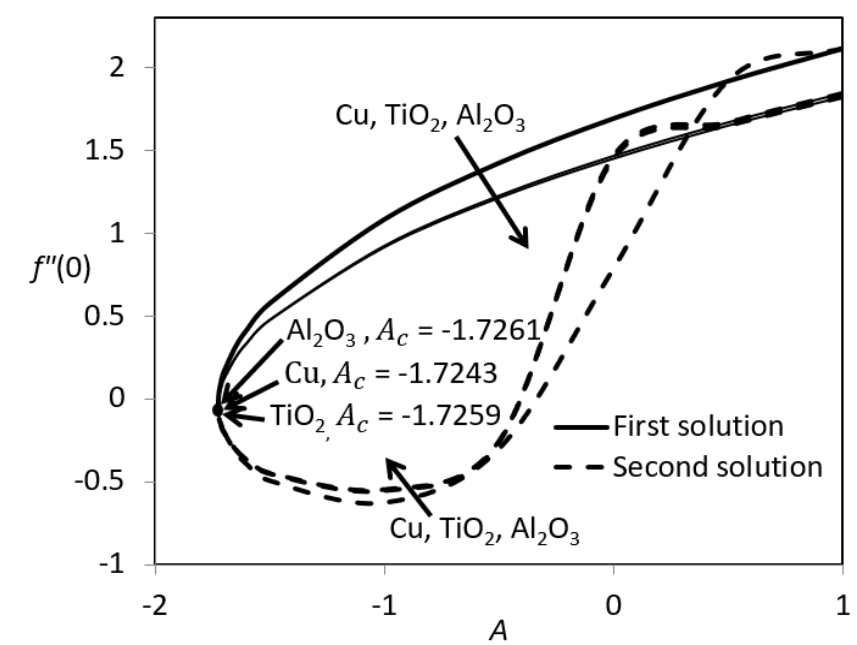

Fig. 14. Variation of $f^{\prime \prime}(0)$ with $A$ for different nanoparticles when $\varepsilon=-0.5$ (shrinking), $\sigma=0.1$ and $\varphi=0.1$ 


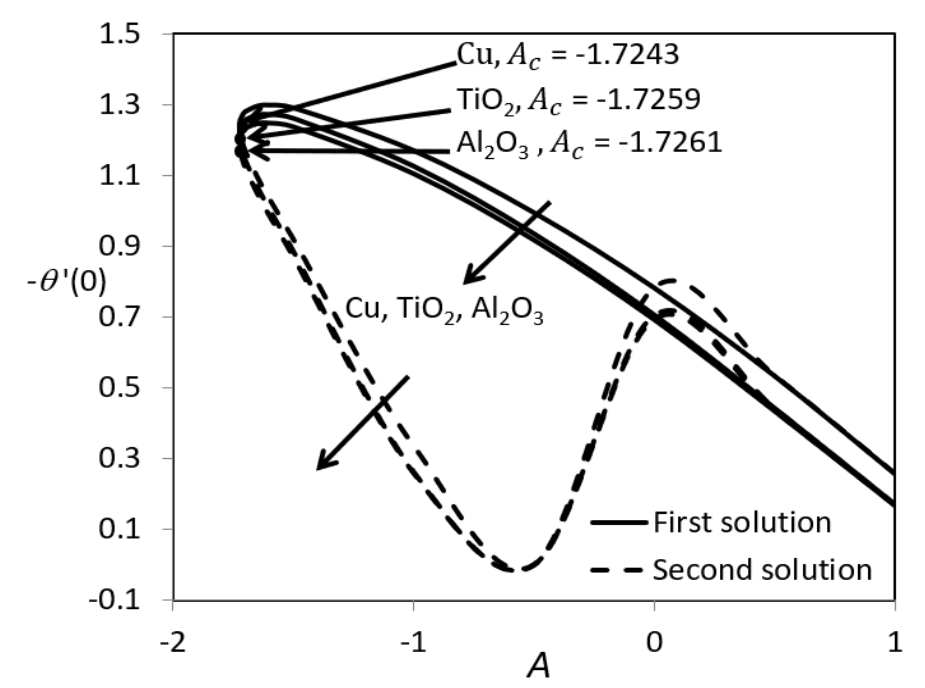

Fig. 15. Variation of $-\theta^{\prime}(0)$ with $A$ for different nanoparticles when $\varepsilon=-0.5$ (shrinking), $\sigma=0.1$ and $\varphi=0.1$

The variations of local skin friction coefficient and local Nusselt number with $\varphi$ for different nanoparticles namely $\mathrm{Cu}, \mathrm{TiO}_{2}$ and $\mathrm{Al}_{2} \mathrm{O}_{3}$ are depicted in Figure 16 and Figure 17. Both figures show that $C_{f} \operatorname{Re}_{x}^{1 / 2}$ and $N u_{x} \operatorname{Re}_{x}^{-1 / 2}$ increase as $\varphi$ in the base fluid increases, and $\mathrm{Cu}$ is proven to have a maximum value of heat transfer rate and friction, while Titania has the lowest. These results are in line as displayed in Table 1 where $\mathrm{Cu}$ has the highest thermal conductivity, and Titania has the lowest thermal conductivity. A similar observation has been reported by Aghamajidi et al., [53].

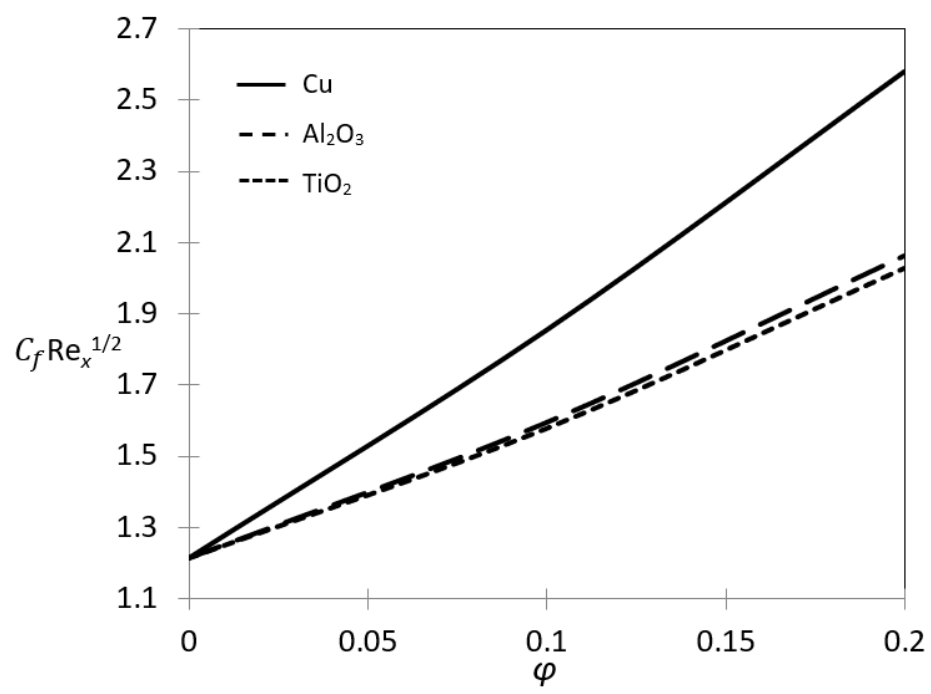

Fig. 16. Variation of skin friction coefficient with $\varphi$ for different nanoparticles when $\varepsilon=-0.5$ (shrinking), $\sigma=0.1$ and $A=-0.5$ 


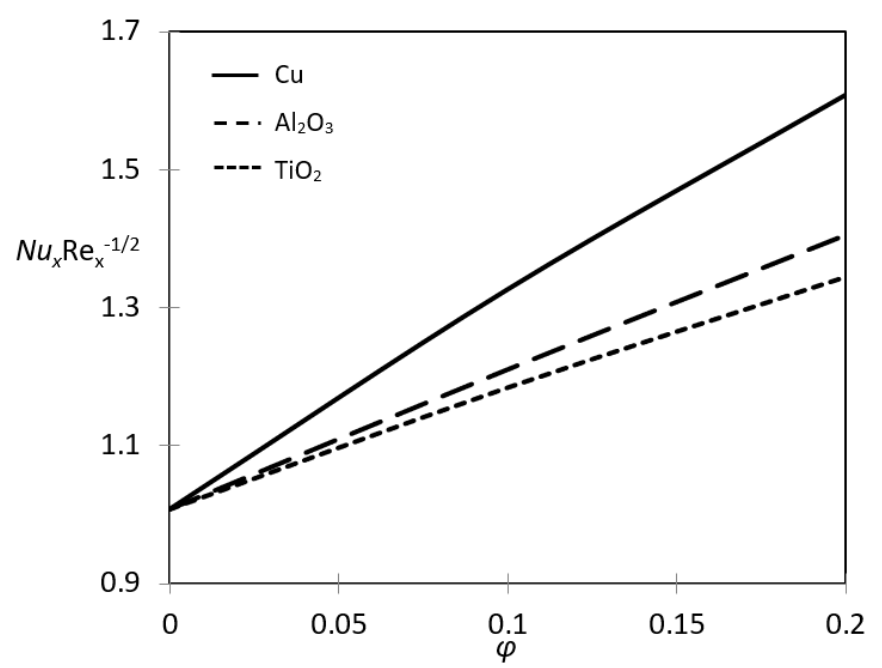

Fig. 17. Variation of local Nusselt number with $\varphi$ for different nanoparticles when $\varepsilon=-0.5$ (shrinking), $\sigma=0.1$ and $A=-0.5$

Figure 18 to Figure 25 represent the velocity and temperature profiles for different parameters, which are nanoparticle volume fraction $\varphi$ (see Figure 18 and Figure 19), types of nanoparticles (see Figure 20 and Figure 21), stretching/shrinking parameter $\varepsilon$ (see Figure 22 and Figure 23), and slip velocity parameter $\sigma$ (see Figure 24 and Figure 25), respectively. These profiles are displayed to show that the far-field boundary conditions (9) are fulfilled asymptotically and support the existence of dual solutions as illustrated in Figure 2 to Figure 15. Based on Figure 18, increasing $\varphi$ for the first solutions tends to increase the velocity profiles and velocity gradient, which gives rise to the value of $f^{\prime \prime}(0)$ as depicted in Figure 2. Figure 19 shows that the temperature profile increases with increasing $\varphi$ when $\varepsilon=-0.5$, which implies the decrease of $\left|-\theta^{\prime}(0)\right|$ as shown in Figure 3. An increment of slip velocity parameter $\sigma$ leads to accelerating the velocity profile and decelerating the temperature profile, which in turn increases the velocity and temperature gradients at the surface. These findings align with the results presented in Figure 4 and Figure 10 (for certain values of $\varepsilon$ and $A$ ) and Figure 5 and Figure 11 (for all values of $\varepsilon$ and $A$ considered), respectively. As can be seen from these figures, the boundary layer thickness for the first solution is smaller than the second solution as reported by many researchers such as Aladdin et al., [43] and Mousavi et al., [54].

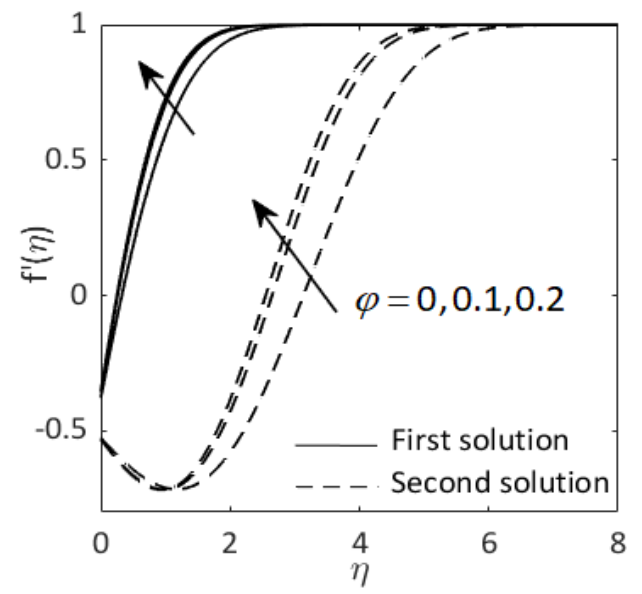

Fig. 18. Velocity profiles for different $\varphi$ of $\mathrm{Cu}-\mathrm{H}_{2} \mathrm{O}$ nanofluid when $\sigma=0.1, A=-0.5$ and $\varepsilon=-0.5$ (shrinking)

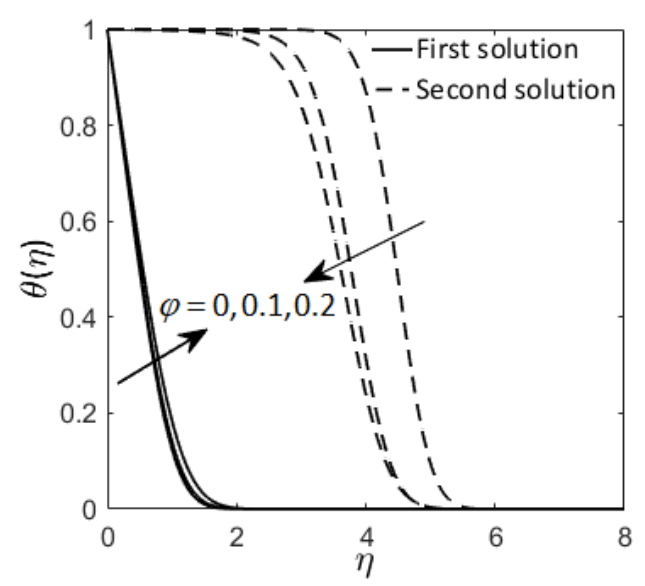

Fig. 19. Temperature profiles for different $\varphi$ of $\mathrm{Cu}-\mathrm{H}_{2} \mathrm{O}$ nanofluid when $\sigma=0.1, A=-0.5$ and $\varepsilon=-0.5$ (shrinking) 


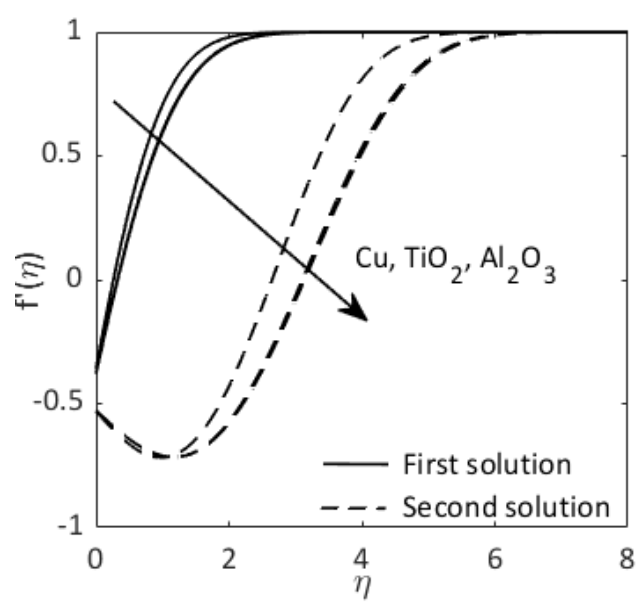

Fig. 20. Velocity profiles for different nanoparticles when $\varphi=0.1, \sigma=0.1$, $A=-0.5$ and $\varepsilon=-0.5$ (shrinking)

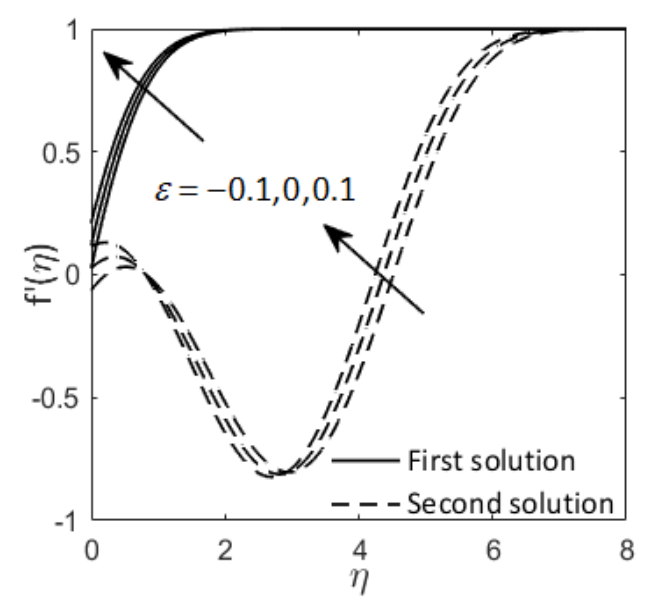

Fig. 22. Velocity profiles for different $\varepsilon$ of $\mathrm{Cu}-\mathrm{H}_{2} \mathrm{O}$ nanofluid when $\sigma=0.1$, $\phi=0.1$ and $A=-0.5$

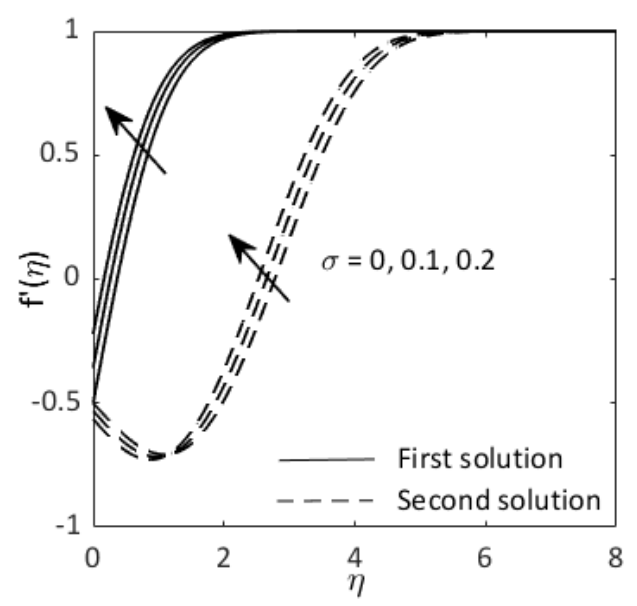

Fig. 24. Velocity profiles for different $\sigma$ of $\mathrm{Cu}-\mathrm{H}_{2} \mathrm{O}$ nanofluid when $\varphi=0.1$ and $A=-0.5$ and $\varepsilon=-0.5$ (shrinking)

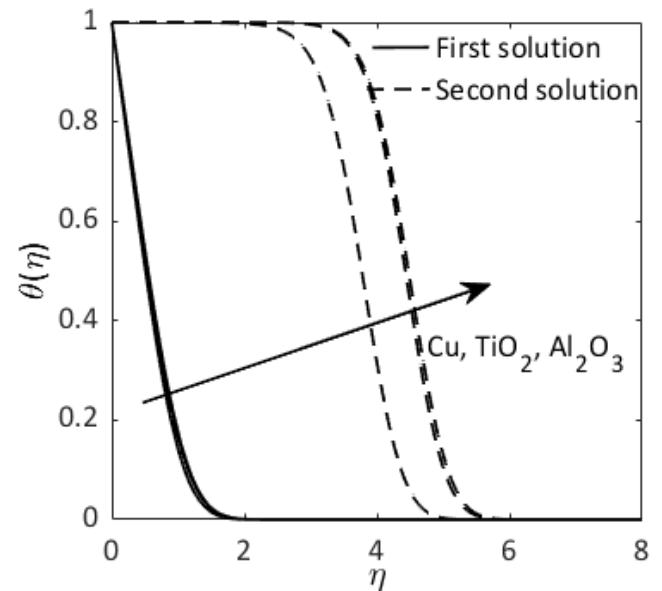

Fig. 21. Temperature profiles for different nanoparticles when $\phi=0.1, \sigma=0.1$, $A=-0.5$ and $\varepsilon=-0.5$ (shrinking)

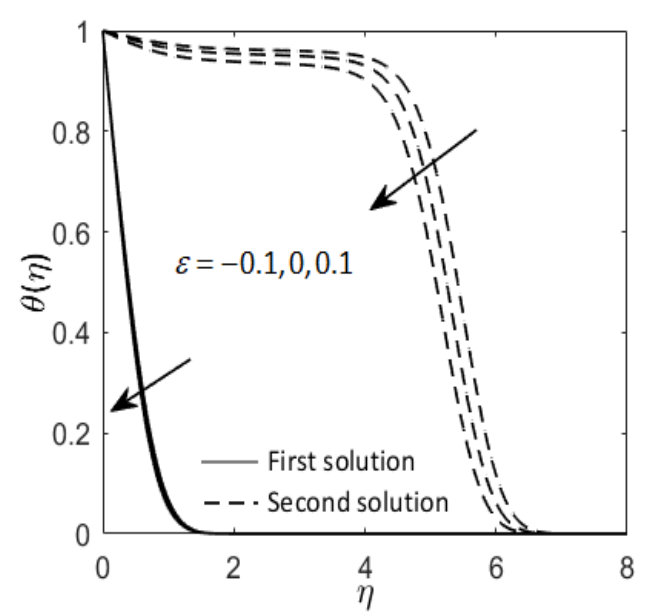

Fig. 23. Temperature profiles for different $\varepsilon$ of $\mathrm{Cu}-\mathrm{H}_{2} \mathrm{O}$ nanofluid when $\sigma=0.1$, $\varphi=0.1$ and $A=-0.5$

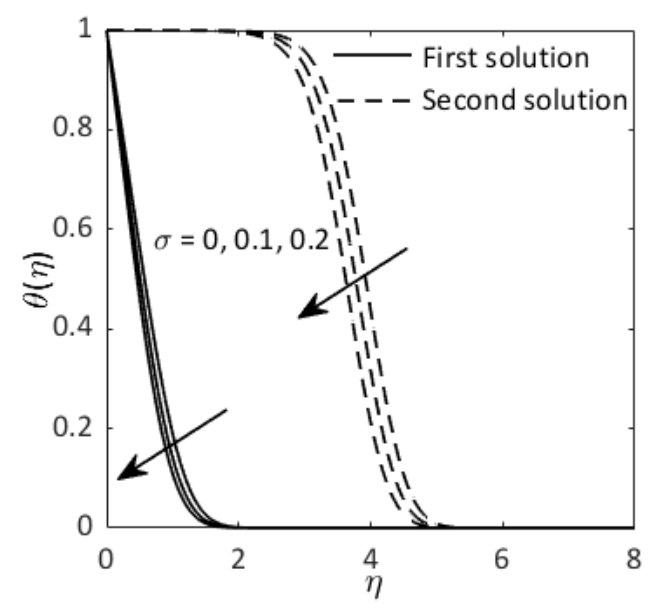

Fig. 25. Temperature profiles for different $\sigma$ of $\mathrm{Cu}-\mathrm{H}_{2} \mathrm{O}$ nanofluid when $\phi=0.1$ and $A=-0.5$ and $\varepsilon=-0.5$ (shrinking) 
Since dual solutions are obtained in this study, the stability analysis is performed to determine the stability of solutions by finding the smallest eigen value $\gamma$. The solution with positive value of $\gamma$ denotes there is initial decay of disturbance in the flow; hence, the solution is considered stable. Meanwhile, the negative value represents the initial disturbance growth in the flow where the solution is identified as unstable. The values of $\gamma$ are obtained by solving Eq. (18) to Eq. (20) using bvp4c solver in MATLAB software. The smallest eigenvalues for the different values of $A$ and $\varphi$ when the sheet is shrunk are presented in Table 4. As can be retrieved from Table 4, the positive values of $\gamma$ are obtained for first solution while the negative values resemble the second solution. As a result, the first solution is stable and realizable, whereas the second solution is unstable, which is consistent with the previous study $[43,44,46,55]$.

\section{Table 4}

The smallest eigenvalues for different values of $A$ and different nanoparticles volume fraction $\varphi$ when $\varepsilon=-0.5$ (shrinking), $\sigma=0.1$ and $\operatorname{Pr}=$

\begin{tabular}{llll}
6.2 & \multicolumn{3}{l}{} \\
\hline$\varphi$ & $A$ & First solution $\gamma$ & Second solution $\gamma$ \\
\hline 0.1 & -1.724 & 0 & -0.09022 \\
& -1.723 & 0.01476 & -0.12901 \\
& -1.721 & 0.05756 & -0.17283 \\
0.2 & -1.724 & 0.00809 & -0.02048 \\
& -1.723 & 0.05967 & -0.07271 \\
& -1.721 & 0.10564 & -0.11999 \\
\hline
\end{tabular}

\section{Conclusion}

The unsteady stagnation-point flow and heat transfer over stretching/shrinking sheet with the slip velocity effect in nanofluids were studied numerically through the Tiwari and Das model. The governing equations were transformed into partial differential equations using the introduced dimensionless similarity variables. The numerical solutions were obtained using the bvp4c solver in MATLAB software and presented in tables and graphical forms. The stability analysis was performed to identify which solution was stable and physically realizable. This study had shown a good agreement with the previous work. Below are the conclusions that could be drawn from this study:

i. Dual solutions were found for a certain range of unsteadiness as well as stretching/shrinking parameters.

ii. Increasing slip velocity and nanoparticle volume fraction tend to increase the friction and heat transfer at the surface with the stretching/shrinking parameter. However, the changes in the unsteadiness parameter showed the opposite findings when nanoparticle volume fraction was increased.

iii. The nanoparticle volume fractions, slip velocity, stretching/shrinking parameter, and unsteadiness parameter play a role in influencing the range of solutions obtained. A higher value of slip velocity towards the stretching/shrinking parameter increased the range of solutions.

iv. Copper nanoparticles give the highest friction and heat transfer rate at the surface compared to Titania and Alumina.

v. By performing stability analysis, the first solution was found to be stable and physically realizable. 


\section{Acknowledgement}

We would like to express an appreciation to the Universiti Teknologi MARA and Fundamental Research Grant Scheme (FRGS/1/2017/STG06/UiTM/02/9) from the Ministry of Higher Education, Malaysia for the financial support received.

\section{References}

[1] Schlichting, H. Boundary Layer Theory. 7th edition. McGraw-Hill, New York, 1979.

[2] Thipse, S. S. Advanced Thermodynamics. Alpha Science International Limited, 2013.

[3] Yang, Junlin, Rolf Bos, Gerald F. Belder, Jan Engel, and Henk J. Busscher. "Deposition of oral bacteria and polystyrene particles to quartz and dental enamel in a parallel plate and stagnation point flow chamber." Journal of Colloid and Interface Science 220, no. 2 (1999): 410-418. https://doi.org/10.1006/jcis.1999.6539

[4] Montecchio, Francesco, Henry Persson, Klas Engvall, Jack Delin, and Roberto Lanza. "Development of a stagnation point flow system to screen and test $\mathrm{TiO}_{2}$-based photocatalysts in air purification applications." Chemical Engineering Journal 306 (2016): 734-744. https://doi.org/10.1016/j.cej.2016.07.117

[5] Bachok, Norfifah, Anuar Ishak, and loan Pop. "The boundary layers of an unsteady stagnation-point flow in a nanofluid." International Journal of Heat and Mass Transfer 55, no. 23-24 (2012): 6499-6505. https://doi.org/10.1016/j.ijheatmasstransfer.2012.06.050

[6] Bhattacharyya, Krishnendu. "Heat transfer analysis in unsteady boundary layer stagnation-point flow towards a shrinking/stretching sheet." Ain Shams Engineering Journal 4, no. 2 (2013): 259-264. https://doi.org/10.1016/i.asej.2012.07.002

[7] Aman, Fazlina, Anuar Ishak, and Ioan Pop. "Magnetohydrodynamic stagnation-point flow towards a stretching/shrinking sheet with slip effects." International Communications in Heat and Mass Transfer 47 (2013): 68-72. https://doi.org/10.1016/i.icheatmasstransfer.2013.06.005

[8] Sharma, Rajesh, Anuar Ishak, and Ioan Pop. "Stability analysis of magnetohydrodynamic stagnation-point flow toward a stretching/shrinking sheet." Computers \& Fluids $102 \quad$ (2014): 94-98. https://doi.org/10.1016/i.compfluid.2014.06.022

[9] Ishak, Anuar, Roslinda Nazar, Norihan M. Arifin, and Ioan Pop. "Dual solutions in mixed convection flow near a stagnation point on a vertical porous plate." International Journal of Thermal Sciences 47, no. 4 (2008): $417-422$. https://doi.org/10.1016/i.ijthermalsci.2007.03.005

[10] Hayat, T., and M. Nawaz. "Unsteady stagnation point flow of viscous fluid caused by an impulsively rotating disk." Journal of the Taiwan Institute of Chemical Engineers 42, no. 1 (2011): 41-49. https://doi.org/10.1016/i.jtice.2010.04.006

[11] Lok, Y. Y., J. H. Merkin, and I. Pop. "Mixed convection flow near the axisymmetric stagnation point on a stretching or shrinking cylinder." International Journal of Thermal Sciences 59 (2012): 186-194. https://doi.org/10.1016/i.ijthermalsci.2012.04.008

[12] Roşca, Alin V., Natalia C. Roşca, and loan Pop. "Axisymmetric stagnation point flow and heat transfer towards a permeable moving flat plate with surface slip condition." Applied Mathematics and Computation 233 (2014): 139151. https://doi.org/10.1016/i.amc.2014.01.130

[13] Mahabaleshwar, U. S., K. R. Nagaraju, M. N. Nadagoud, R. Bennacer, and Dumitru Baleanu. "An MHD viscous liquid stagnation point flow and heat transfer with thermal radiation and transpiration." Thermal Science and Engineering Progress 16 (2020): 100379. https://doi.org/10.1016/i.tsep.2019.100379

[14] Ghasemi, S. E., and Mohammad Hatami. "Solar radiation effects on MHD stagnation point flow and heat transfer of a nanofluid over a stretching sheet." Case Studies in Thermal Engineering 25 (2021): 100898. https://doi.org/10.1016/i.csite.2021.100898

[15] Mathew, Alphonsa, Sujesh Areekara, A. S. Sabu, and S. Saleem. "Significance of multiple slip and nanoparticle shape on stagnation point flow of silver-blood nanofluid in the presence of induced magnetic field." Surfaces and Interfaces (2021): 101267. https://doi.org/10.1016/i.surfin.2021.101267

[16] Aly, Emad H., and I. Pop. "MHD flow and heat transfer near stagnation point over a stretching/shrinking surface with partial slip and viscous dissipation: Hybrid nanofluid versus nanofluid." Powder Technology 367 (2020): 192205. https://doi.org/10.1016/i.powtec.2020.03.030

[17] Jamaludin, Anuar, Kohilavani Naganthran, Roslinda Nazar, and loan Pop. "MHD mixed convection stagnation-point flow of $\mathrm{Cu}-\mathrm{Al}_{2} \mathrm{O}_{3} /$ water hybrid nanofluid over a permeable stretching/shrinking surface with heat source/sink." European Journal of Mechanics-B/Fluids 84 (2020): 71-80. https://doi.org/10.1016/i.euromechflu.2020.05.017 
[18] Zainal, Nurul Amira, Roslinda Nazar, Kohilavani Naganthran, and Ioan Pop. "MHD mixed convection stagnation point flow of a hybrid nanofluid past a vertical flat plate with convective boundary condition." Chinese Journal of Physics 66 (2020): 630-644. https://doi.org/10.1016/i.cjph.2020.03.022

[19] Uddin, Ziya, Korimerla Sai Vishwak, and Souad Harmand. "Numerical duality of MHD stagnation point flow and heat transfer of nanofluid past a shrinking/stretching sheet: Metaheuristic approach." Chinese Journal of Physics 73 (2021): 442-461. https://doi.org/10.1016/i.cjph.2021.07.018

[20] Bang, In Cheol, and Gyunyoung Heo. "An axiomatic design approach in development of nanofluid coolants." Applied Thermal Engineering 29, no. 1 (2009): 75-90. https://doi.org/10.1016/j.applthermaleng.2008.02.004

[21] Che Sidik, Nor Azwadi, N. G. Yen Cheong, and Alireza Fazeli. "Computational Analysis of Nanofluids in Vehicle Radiator." In Applied Mechanics and Materials, vol. 695, pp. 539-543. Trans Tech Publications Ltd, 2015. https://doi.org/10.4028/www.scientific.net/AMM.695.539

[22] Buongiorno, Jacopo. "Convective transport in nanofluids." Journal of Heat Transfer 128, no. 3 (2006): $240-250$. https://doi.org/10.1115/1.2150834

[23] Tiwari, Raj Kamal, and Manab Kumar Das. "Heat transfer augmentation in a two-sided lid-driven differentially heated square cavity utilizing nanofluids." International Journal of Heat and Mass Transfer 50, no. 9-10 (2007): 2002-2018. https://doi.org/10.1016/j.ijheatmasstransfer.2006.09.034

[24] Devi, SP Anjali, and Julie Andrews. "Laminar boundary layer flow of nanofluid over a flat plate." International Journal of Applied Mathematics and Mechanics 7, no. 6 (2011): 52-71.

[25] Srinivasacharya, D., Upendar Mendu, and K. Venumadhav. "MHD boundary layer flow of a nanofluid past a wedge." Procedia Engineering 127 (2015): 1064-1070. https://doi.org/10.1016/i.proeng.2015.11.463

[26] Malvandi, A., F. Hedayati, and D. D. Ganji. "Nanofluid flow on the stagnation point of a permeable non-linearly stretching/shrinking sheet." Alexandria Engineering Journal 57, no. $4 \quad$ (2018): 2199-2208. https://doi.org/10.1016/i.aej.2017.08.010

[27] Jafar, Ahmad Banji, Sharidan Shafie, and Imran Ullah. "MHD radiative nanofluid flow induced by a nonlinear stretching sheet in a porous medium." Heliyon 6, no. 6 (2020): e04201. https://doi.org/10.1016/i.heliyon.2020.e04201

[28] Ferdows, M., S. O. Adesanya, Faris Alzahrani, and T. A. Yusuf. "Numerical investigation of a boundary layer waterbased nanofluid flow with induced magnetic field." Physica A: Statistical Mechanics and its Applications 570 (2021): 125492. https://doi.org/10.1016/j.physa.2020.125492

[29] Johan, Nurul Aisyah, and Syahira Mansur. "Boundary Layer Flow of Dusty Nanofluid over Stretching Sheet with Partial Slip Effects." Journal of Advanced Research in Fluid Mechanics and Thermal Sciences 87, no. 2 (2021): 118126. https://doi.org/10.37934/arfmts.87.2.118126

[30] Nasir, Faiza Mohamed, Mohd Zulkifly Abdullah, and Mior Firdaus Mior Abdul Majid. "Empirical Viscosity Modeling for $\mathrm{SiO}_{2}$ and $\mathrm{Al}_{2} \mathrm{O}_{3}$ Nanofluids using the Response Surface Method." Journal of Advanced Research in Fluid Mechanics and Thermal Sciences 75, no. 3 (2020): 63-72. https://doi.org/10.37934/arfmts.75.3.6372

[31] Sannad, Mohamed, Btissam Abourida, and El Houcine Belarche. "Numerical Study of the Effect of the Nanofluids Type and The Size of the Heating Sections on Heat Transfer for Cooling Electronic Components." Journal of Advanced Research in Fluid Mechanics and Thermal Sciences 75, no. 2 (2020): 168-184. https://doi.org/10.37934/arfmts.75.2.168184

[32] Jahan, Sultana, M. Ferdows, M. D. Shamshuddin, and Khairy Zaimi. "Effects of Solar Radiation and Viscous Dissipation on Mixed Convective Non-Isothermal Hybrid Nanofluid over Moving Thin Needle." Journal of Advanced Research in Micro and Nano Engineering 3, no. 1 (2021): 1-11.

[33] Uddin, Ziya, Rishi Asthana, Mukesh Kumar Awasthi, and Hamdy Hassan. "A metaheuristic approach for the comparative study of MHD flow of nano liquids in a semi-porous channel." International Journal for Computational Methods in Engineering Science and Mechanics (2021): 1-8. https://doi.org/10.1080/15502287.2021.1916700

[34] Uddin, Ziya, Souad Harmand, and Shahid Ahmed. "Computational modeling of heat transfer in rotating heat pipes using nanofluids: A numerical study using PSO." International Journal of Thermal Sciences 100, no. 112 (2017): 4454. https://doi.org/10.1016/i.ijthermalsci.2016.09.035

[35] Uddin, Z., R. Asthana, M. Kumar Awasthi, and S. Gupta. "Steady MHD flow of nano-fluids over a rotating porous disk in the presence of heat generation/absorption: a numerical study using PSO." Journal of Applied Fluid Mechanics (JAFM) 10, no. 3 (2017): 871-879. https://doi.org/10.18869/acadpub.jafm.73.240.26650

[36] Uddin, Ziya, Manoj Kumar, and Souad Harmand. "Influence of thermal radiation and heat generation/absorption on MHD heat transfer flow of a micropolar fluid past a wedge considering hall and ion slip currents." Thermal Science 18, no. suppl. 2 (2014): 489-502. https://doi.org/10.2298/TSCI110712085U

[37] Uddin, Ziya, and Souad Harmand. "Natural convection heat transfer of nanofluids along a vertical plate embedded in porous medium." Nanoscale Research Letters 8, no. 1 (2013): 1-19. https://doi.org/10.1186/1556-276X-8-64 
[38] Wang, C. Y. "Flow due to a stretching boundary with partial slip-an exact solution of the Navier-Stokes equations." Chemical Engineering Science 57, no. 17 (2002): 3745-3747. https://doi.org/10.1016/S0009-2509(02)00267-1

[39] Jamil, Muhammad, and Najeeb Alam Khan. "Slip effects on fractional viscoelastic fluids." International Journal of Differential Equations 2011 (2011). https://doi.org/10.1155/2011/193813

[40] Mukhopadhyay, Swati. "Slip effects on MHD boundary layer flow over an exponentially stretching sheet with suction/blowing and thermal radiation." Ain Shams Engineering Journal 4, no. 3 (2013): $485-491$. https://doi.org/10.1016/i.asej.2012.10.007

[41] Pandey, Alok Kumar, and Manoj Kumar. "Boundary layer flow and heat transfer analysis on Cu-water nanofluid flow over a stretching cylinder with slip." Alexandria Engineering Journal 56, no. 4 (2017): 671-677. https://doi.org/10.1016/j.aej.2017.01.017

[42] Hussain, Azad, Sana Afzal, Rizwana Rizwana, and M. Y. Malik. "MHD stagnation point flow of a Casson fluid with variable viscosity flowing past an extending/shrinking sheet with slip effects." Physica A: Statistical Mechanics and Its Applications 553 (2020): 124080. https://doi.org/10.1016/i.physa.2019.124080

[43] Aladdin, Nur Adilah Liyana, Norfifah Bachok, and I. Pop. "Boundary layer flow and heat transfer of $\mathrm{Cu}-\mathrm{Al}_{2} \mathrm{O}_{3} /$ water over a moving horizontal slender needle in presence of hydromagnetic and slip effects." International Communications in Heat and Mass Transfer $123 \quad$ (2021): 105213. https://doi.org/10.1016/j.icheatmasstransfer.2021.105213

[44] Merkin, J. H. "On dual solutions occurring in mixed convection in a porous medium." Journal of Engineering Mathematics 20, no. 2 (1986): 171-179. https://doi.org/10.1007/BF00042775

[45] Weidman, P. D., D. G. Kubitschek, and A. M. J. Davis. "The effect of transpiration on self-similar boundary layer flow over moving surfaces." International Journal of Engineering Science 44, no. 11-12 (2006): $730-737$. https://doi.org/10.1016/j.ijengsci.2006.04.005

[46] Harris, S. D., D. B. Ingham, and I. Pop. "Mixed convection boundary-layer flow near the stagnation point on a vertical surface in a porous medium: Brinkman model with slip." Transport in Porous Media 77, no. 2 (2009): $267-285$. https://doi.org/10.1007/s11242-008-9309-6

[47] Mahapatra, Tapas Ray, Samir Kumar Nandy, Kuppalapalle Vajravelu, and Robert A. Van Gorder. "Stability analysis of the dual solutions for stagnation-point flow over a non-linearly stretching surface." Meccanica 47, no. 7 (2012): 1623-1632. https://doi.org/10.1007/s11012-012-9541-6

[48] Roşca, Natalia C., and Ioan Pop. "Mixed convection stagnation point flow past a vertical flat plate with a second order slip: heat flux case." International Journal of Heat and Mass Transfer 65 (2013): $102-109$. https://doi.org/10.1016/j.ijheatmasstransfer.2013.05.061

[49] Ishak, Anuar. "Dual Solutions in Mixed Convection Boundary Layer Flow: A Stability Analysis." International Journal of Mathematical and Computational Sciences 8, no. 9 (2014): 1216-1219.

[50] Bhattacharyya, Krishnendu, Swati Mukhopadhyay, and G. C. Layek. "Slip effects on boundary layer stagnation-point flow and heat transfer towards a shrinking sheet." International Journal of Heat and Mass Transfer 54, no. 1-3 (2011): 308-313. https://doi.org/10.1016/j.ijheatmasstransfer.2010.09.041

[51] Oztop, Hakan F., and Eiyad Abu-Nada. "Numerical study of natural convection in partially heated rectangular enclosures filled with nanofluids." International Journal of Heat and Fluid Flow 29, no. 5 (2008): 1326-1336. https://doi.org/10.1016/j.ijheatfluidflow.2008.04.009

[52] Shampine, Lawrence F., lan Gladwell, and S. Thompson. Solving ODEs with MATLAB. Cambridge University Press, 2003. https://doi.org/10.1017/CBO9780511615542

[53] Aghamajidi, Mohammad, MohammadEftekhari Yazdi, Saeed Dinarvand, and loan Pop. "Tiwari-Das nanofluid model for magnetohydrodynamics (MHD) natural-convective flow of a nanofluid adjacent to a spinning down-pointing vertical cone." Propulsion and Power Research 7, no. 1 (2018): 78-90. https://doi.org/10.1016/j.jppr.2018.02.002

[54] Mousavi, Seyed Mahdi, Mohammadreza Nademi Rostami, Mohammad Yousefi, Saeed Dinarvand, loan Pop, and Mikhail A. Sheremet. "Dual solutions for Casson hybrid nanofluid flow due to a stretching/shrinking sheet: A new combination of theoretical and experimental models." Chinese Journal of Physics 71 (2021): 574-588. https://doi.org/10.1016/i.cjph.2021.04.004

[55] Mustafa, Irfan, Zaheer Abbas, Ayesha Arif, Tariq Javed, and Abuzar Ghaffari. "Stability analysis for multiple solutions of boundary layer flow towards a shrinking sheet: analytical solution by using least square method." Physica A: Statistical Mechanics and its Applications 540 (2020): 123028. https://doi.org/10.1016/i.physa.2019.123028 